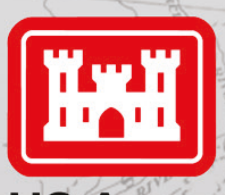

US Army Corps of Engineers ${ }_{\circledast}$

\title{
Two-Dimensional Hydraulics and Sediment Transport Modeling of the Racetrack Reach of the Mississippi River, 1965-1969
}

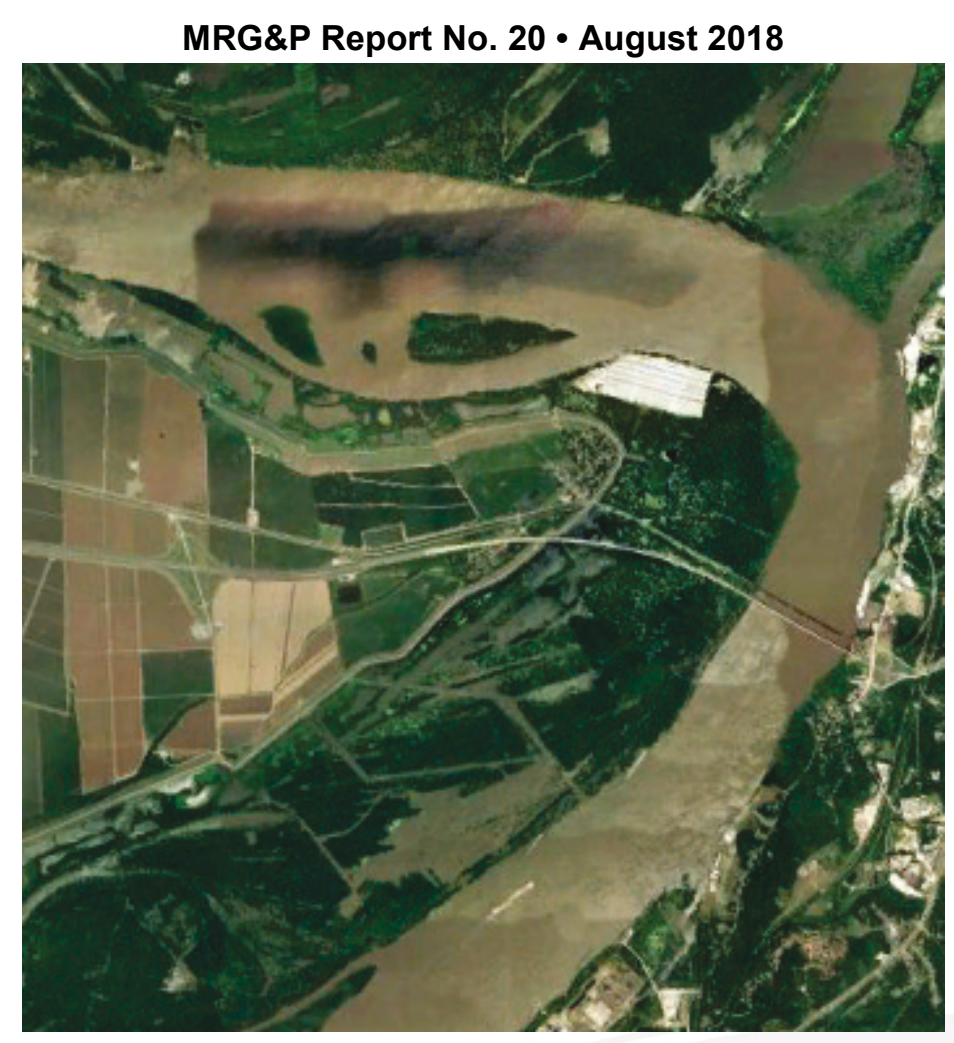

$\mathrm{MRG \& P}$

Mississippi River Geomorphology \&

Potamology Program 


\section{Two-Dimensional Hydraulics and Sediment Transport Modeling of the Racetrack Reach of the Mississippi River, 1965-1969}

James R. Leech, David P. May, and Tate O. McAlpin

Coastal and Hydraulics Laboratory

U.S. Army Engineer Research and Development Center

3909 Halls Ferry Road

Vicksburg, MS 39180-6199

Barbara Kleiss

U.S. Army Corps of Engineers, Mississippi Valley Division 1400 Walnut Street

Vicksburg, MS 39180

Final report

Approved for public release; distribution is unlimited.

Prepared for U.S. Army Corps of Engineers, Mississippi Valley Division Mississippi River Geomorphology \& Potamology Program 1400 Walnut Street Vicksburg, MS 39180

Under Project 470711, "Multi-Dimensional Modeling of the Mississippi River" 


\section{Abstract}

This report documents the development, calibration, and validation of a numerical model for the Racetrack Reach of the Mississippi River between the Vicksburg, MS, Interstate-20 Bridge and approximately 12 miles downstream conducted for the U.S. Army Corps of Engineers, Mississippi Valley Division, Vicksburg, MS. The investigation was conducted via a combination of historical field data collection and numerical modeling of the hydraulics and sediment transport. The objectives were to model flow conditions and sediment transport from 1965 through 1969 and compare to historical surveys from 1965 and 1969 on the Mississippi River. A detailed Adaptive Hydraulics model was developed for this reach of the river. The model domain extends from 10 miles upstream of the Mississippi River Bridge in Vicksburg, MS, to 24 miles downstream of the bridge and adjacent portions of the Mississippi River and its floodplain. Unsteady flow simulations were evaluated for the time from 1965 through 1969. For this particular model application, the Wright-Parker suspended sediment entrainment function and the Meyer Peter Mueller with Wong Parker Correction bed-load entrainment function results best replicated the depositional/erosion patterns and magnitudes. The choice of hiding factor did not have a noticeable impact on the results.

DISCLAIMER: The contents of this report are not to be used for advertising, publication, or promotional purposes. Citation of trade names does not constitute an official endorsement or approval of the use of such commercial products. All product names and trademarks cited are the property of their respective owners. The findings of this report are not to be construed as an official Department of the Army position unless so designated by other authorized documents. 


\section{Contents}

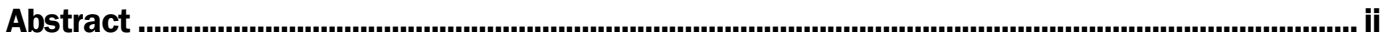

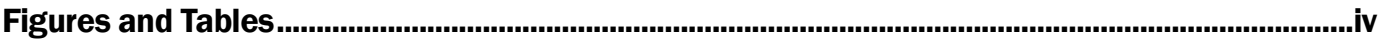

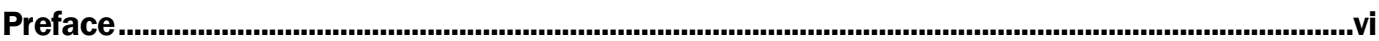

Unit Conversion Factors ........................................................................................................................vii

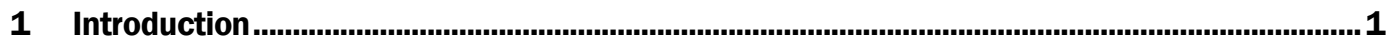

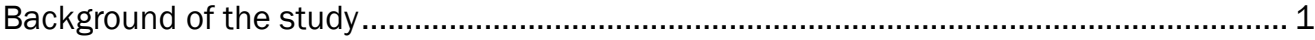

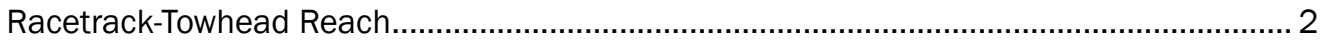

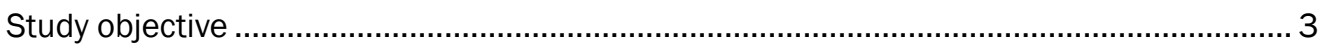

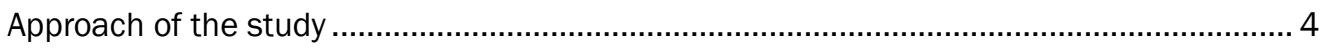

2 Model Description........................................................................................................................ 5

Adaptive Hydraulics (AdH) and SEDLIB ............................................................. 5

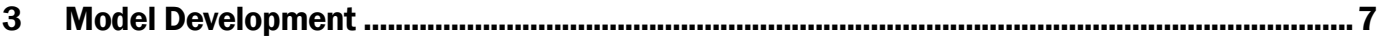

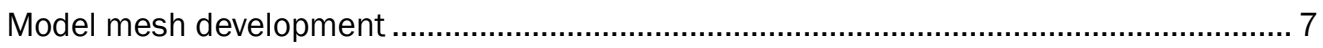

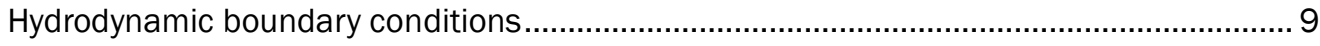

Tailwater specification .................................................................................................... 10

Inflow boundary specification........................................................................................... 10

Sediment boundary conditions and bed initialization................................................. 11

Noncohesive sediment boundary conditions and bed initialization..................................... 11

4 Calibration and Validation ..................................................................................................14

Hydrodynamic calibration and validation .................................................................. 14

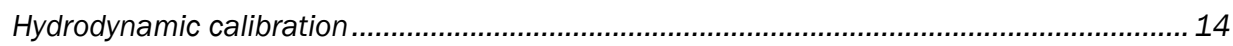

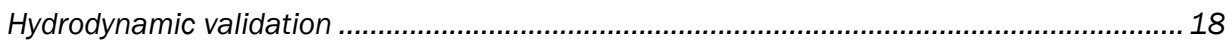

5 Sediment Transport ...................................................................................................................22

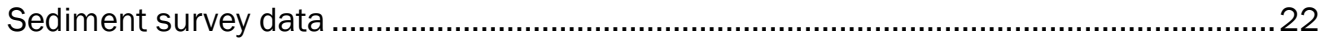

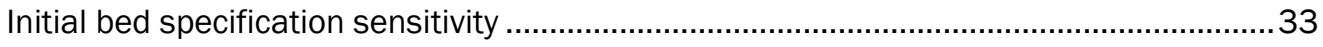

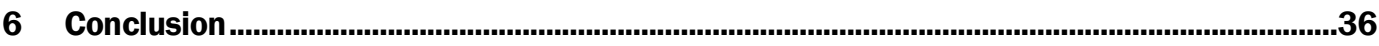

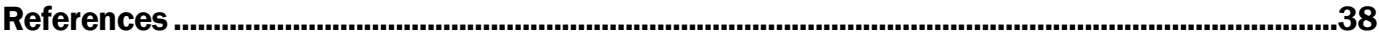

Appendix A: Mississippi River Hydrographic Survey Plates for the Racetrack Reach

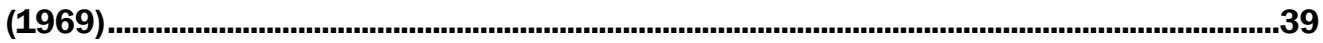

\section{Report Documentation Page}




\section{Figures and Tables}

\section{Figures}

Figure 1-1. Racetrack Reach. 3

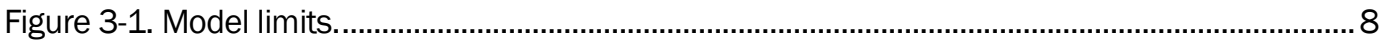

Figure 3-2. Model mesh of channel and overbank. ………………………………………......

Figure 3-3. Gate and interpolated water levels. ...................................................................................10

Figure 4-1. River gage location in the model domain. ......................................................................15

Figure 4-2. Roughness assigned by material type................................................................................16

Figure 4-3. 1965 hydrograph. ..................................................................................................

Figure 4-4. 1965 WSE plot: WSE vs. time for Vicksburg...............................................................18

Figure 4-5. 1965 WSE plot: model vs. field for Vicksburg. .............................................................18

Figure 4-6. 1965-1969 hydrograph. ..............................................................................................19

Figure 4-7. 1965-1969 WSE plot: WSE vs. time for Vicksburg......................................................20

Figure 4-8. 1965-1969 WSE plot: model vs. field for Vicksburg.....................................................21

Figure 5-1. 1969-1965 observed bed displacement, RM 435 to RM 425 ...................................24

Figure 5-2. 1969-1965 observed bed displacement, RM 425 to RM 410_.....................................24

Figure 5-3. 1969-1965 Model Run 1 bed displacement, RM 435 to RM 425..............................25

Figure 5-4. 1969-1965 Model Run 1 bed displacement, RM 425 to RM 410...............................25

Figure 5-5. 1969-1965 Model Run 2 bed displacement, RM 435 to RM 425 ..............................26

Figure 5-6. 1969-1965 Model Run 2 bed displacement, RM 425 to RM 410................................26

Figure 5-7. 1969-1965 Model Run 3 bed displacement, RM 435 to RM 425 ................................27

Figure 5-8. 1969-1965 Model Run 3 bed displacement, RM 425 to RM 410................................27

Figure 5-9. 1969-1965 Model Run 4 bed displacement, RM 435 to RM 425 ..............................28

Figure 5-10. 1969-1965 Model Run 4 bed displacement, RM 425 to RM 410.............................28

Figure 5-11. 1969-1965 Model Run 5 bed displacement, RM 435 to RM 425.............................29

Figure 5-12. 1969-1965 Model Run 5 bed displacement, RM 425 to RM 410.............................29

Figure 5-13. 1969-1965 Model Run 6 bed displacement, RM 435 to RM 425.............................30

Figure 5-14. 1969-1965 Model Run 6 bed displacement, RM 425 to RM 410.............................30

Figure 5-15. 1969-1965 Model Run 7 bed displacement, RM 435 to RM 425.............................31

Figure 5-16. 1969-1965 Model Run 7 bed displacement, RM 425 to RM 410.............................31

Figure 5-17. 1969-1965 Model Run 8 bed displacement, RM 435 to RM 425............................32

Figure 5-18. 1969-1965 Model Run 8 bed displacement, RM 425 to RM 410 ..............................32

Figure 5-19. Variation in results due to changes in the initialized bed. The left figure is NSE Wright-Parker, NBE Van Rijn, and HID Wu Wang Jia results with NSE Wright-Parker, NBE Van Rijn, and HID Wu Wang Jia spinup bed initialization, and the right figure is NSE Wright-Parker, NBE Van Rijn, and HID Wu Wang Jia results with NSE Wright-Parker, NBE Meyer Peter Mueller with Wong Parker Correction, and HID Eziagaroff spinup bed initialization

Figure 5-20. Variation in results due to changes in the initialized bed. The left figure is NSE Wright-Parker, NBE Meyer Peter Mueller with Wong Parker Correction, and HID 
Eziagaroff results with NSE Wright-Parker, NBE Van Rijn, and HID Wu Wang Jia spinup bed initialization, and the right figure is NSE Wright-Parker, NBE Meyer Peter Mueller with Wong Parker Correction, and HID Eziagaroff results with a NSE Wright-Parker, NBE Meyer Peter Mueller with Wong Parker Correction, and HID Eziagaroff spinup bed initialization

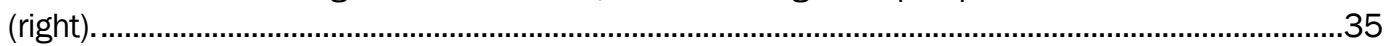

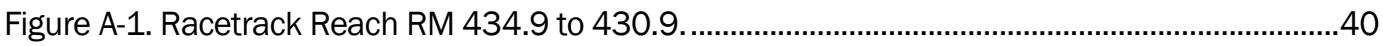

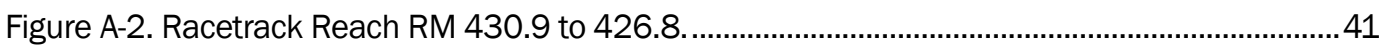

Figure A-3. Racetrack Reach RM 426.8 to 422.9...........................................................................42

\section{Tables}

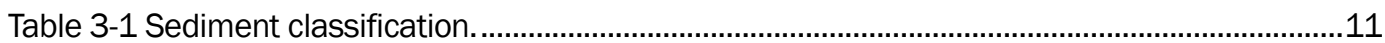

Table 3-2. Applied bed sediment distributions for the river channel. ................................................12

Table 4-1. Manning's $n$-values used in the simulations. .......................................................................17

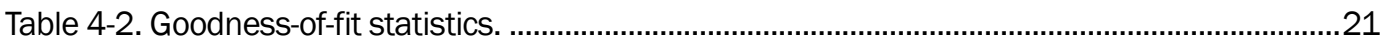

Table 5-1. Racetrack Reach sediment transport runs and algorithms. ............................................23 


\section{Preface}

The research documented in this report was conducted as part of the Mississippi River Geomorphology and Potamology (MRG\&P) Program, Project 470711, "Multi-Dimensional Modeling of the Mississippi River." The MRG\&P is part of the Mississippi River and Tributaries Program (MR\&T) and is managed by the U.S. Army Corps of Engineers (USACE), Mississippi Valley Division (MVD), and Districts. At the time of publication of this report, the MRG\&P Technical Director was Dr. Ty Wamsley. The MVD Commander was MG Richard G. Kaiser. The MVD Director of Programs was Mr. James A. Bodron.

Mississippi River engineering direction and policy advice were provided by the Mississippi River Commission. The Commission members were MG Kaiser, USACE; the Honorable Sam E. Angel; the Honorable James Reeder; the Honorable Norma Jean Mattei, PhD; RDML Shepard Smith, National Oceanic and Atmospheric Administration; MG Mark Toy, USACE; and BG Paul E. Owen, USACE.

The work was performed by the River Engineering Branch of the Flood and Storm Protection Division, U.S. Army Engineer Research and Development Center, Coastal and Hydraulics Laboratory (ERDC-CHL). At the time of publication, Mr. Keith Flowers was Chief, CEERD-HF-R; Dr. Cary Talbot was Chief, CEERD-HF. The Acting Director of ERDC-CHL was Mr. Jeffrey R. Eckstein.

COL Ivan P. Beckman was the Commander of ERDC, and Dr. David W. Pittman was the Director. 


\section{Unit Conversion Factors}

\begin{tabular}{|c|c|c|}
\hline Multiply & By & To Obtain \\
\hline Acres & $4,046.873$ & square meters \\
\hline acre-feet & $1,233.5$ & cubic meters \\
\hline cubic feet & 0.02831685 & cubic meters \\
\hline cubic yards & 0.7645549 & cubic meters \\
\hline Feet & 0.3048 & meters \\
\hline Inches & 0.0254 & meters \\
\hline Knots & 0.5144444 & meters per second \\
\hline miles (nautical) & 1,852 & meters \\
\hline miles (U.S. statute) & $1,609.347$ & meters \\
\hline miles per hour & 0.44704 & meters per second \\
\hline pounds (mass) & 0.45359237 & kilograms \\
\hline pounds (mass) per cubic foot & 16.01846 & kilograms per cubic meter \\
\hline pounds (mass) per cubic inch & $2.757990 \mathrm{E}+04$ & kilograms per cubic meter \\
\hline pounds (mass) per square foot & 4.882428 & kilograms per square meter \\
\hline pounds (mass) per square yard & 0.542492 & kilograms per square meter \\
\hline square feet & 0.09290304 & square meters \\
\hline square miles & $2.589998 \mathrm{E}+06$ & square meters \\
\hline square yards & 0.8361274 & square meters \\
\hline tons (force) & $8,896.443$ & newtons \\
\hline tons (force) per square foot & 95.76052 & kilopascals \\
\hline tons (long) per cubic yard & $1,328.939$ & kilograms per cubic meter \\
\hline tons $(2,000$ pounds, mass $)$ & 907.1847 & kilograms \\
\hline tons ( 2,000 pounds, mass) per square foot & $9,764.856$ & kilograms per square meter \\
\hline Yards & 0.9144 & meters \\
\hline
\end{tabular}




\section{Introduction}

\section{Background of the study}

The Mississippi River and Tributaries (MR\&T) Project is a complex, comprehensive water resources project authorized by the 1928 Flood Control Act following the devastating 1927 flood. The MR\&T Project provides flood damage reduction within the alluvial valley and navigation improvement of the Lower Mississippi River (LMR). The LMR extends approximately 1,000 miles from Cairo, IL, to the Gulf of Mexico. The primary elements of the MR\&T Project include levees, floodways and diversion structures, tributary basin improvements, and channel improvement features such as meander cutoffs, bank stabilization, dikes, and dredging. The historical, present, and future morphology of the LMR reflects an integration of all these features in combination with natural factors: floods and droughts, hurricanes, tectonic activity, geologic outcrops, climatic variability, subsidence, and sea level rise. Understanding how these various factors affect the short- and long-term morphology of the LMR is a complex challenge for the river engineers and scientists responsible for managing this system for flood damage reduction, navigation, habitat restoration, and reduction of the loss of coastal marshes and wetlands in Louisiana. Much of the knowledge about the morphologic character of the LMR was gained through the U.S. Army Corps of Engineers (USACE) Potamology Program, which began in the early 1930 in recognition of the need to develop a better understanding of the underlying principles responsible for the behavior of the river.

The Mississippi River Commission (MRC) Potamology Board was established in 1957. It consisted of representatives from the MRC; the Memphis, Vicksburg (MVK), and New Orleans Districts; and Waterways Experiment Station. Active until 1961, the Board helped foster completion of additional potamology investigations. The Board was re-established in 1963 and expanded to include the entire Lower Mississippi Valley Division; a representative from the St. Louis District was added to the Board. In 1963, the MRC also established a Potamology Research Branch in the Engineering Division to coordinate studies recommended by the Potamology Board. The Board and the Branch were instrumental in completing several investigations (Biedenharn 2014). 


\section{Racetrack-Towhead Reach}

From the 1960 s to 1972 , the potamology studies and programs focus shifted yet again as the MRC worked to develop the best ways to manage troublesome reaches of the river. These activities spawned research and investigative studies, providing much-needed information that advanced the understanding of the complex processes occurring when nature and man-made structures combine to shape the river over time. Potamology Study Reaches include the following:

- Cessions-Henrico

- Smith PT-Terrance

- Terrence Ozark

- Ozark-Eutaw

- Choctaw Bar

- Greenville Reach

- LakePort Towhead

- Kentucky Bend

- Cracraft-Carolina

- Carolina-Baleshed

- Baleshed LDG DF

- Ajax Bar

- Ajax-Cottonwood

- Cottonwood Bar

- Cottonwood-Belle Island

- Belle Island-Milliken Bend

- Milliken Bend-Vicksburg

- Racetrack-Towhead

- Point Pleasant

- Grand Gulf

- Rodney

- Waterproof

- Natchez

- St Catherine

- Bougere
(616.0 to 606.o) River Mile (RM)

(606.0 to 594.0)

(594.0 to 581.0 )

(581.0 to 565.9 )

(565.9 to 550.3 )

(550.3 to 531.1)

(531.1 to 524.1)

(524.1 to 514.7)

(514.7 to 506.5)

(506.5 to 495.5)

(495.5 to 485.7)

(485.7 to 479.7)

(479.7 to 471.9)

(471.9 to 467.7)

(467.7 to 461.3)

(461.3 to 451.7)

(451.7 to 434.9)

(434.9 to 422.7)

(422.7 to 407.3)

(407.3 to 395.1)

(395.1 to 381.3)

(381.3 to 368.1 )

(368.1 to 355.1)

(355.1 to 338.5)

(338.5 to 320.4)

The Racetrack-Towhead Reach (Figure 1-1) is from RM 434.9 to 422.7. Within the Racetrack Reach, a water surface elevation (WSE) gage has historically been located in the vicinity of the current Interstate-20 (I-20) bridge in Vicksburg, MS. The current gage is operated by USACE with measurements prior to 1977 being obtained by the U.S. Geological Survey 
(USGS). Bed material data were obtained for the Racetrack Reach collected at RM 424.6 for 7 November 1968, 11 April 1969, 13 August 1969 and 7 January 1970 . The average sediment size gradations were collected for all reaches in the Potamology Study between 1966 and 1972.

Figure 1-1. Racetrack Reach.

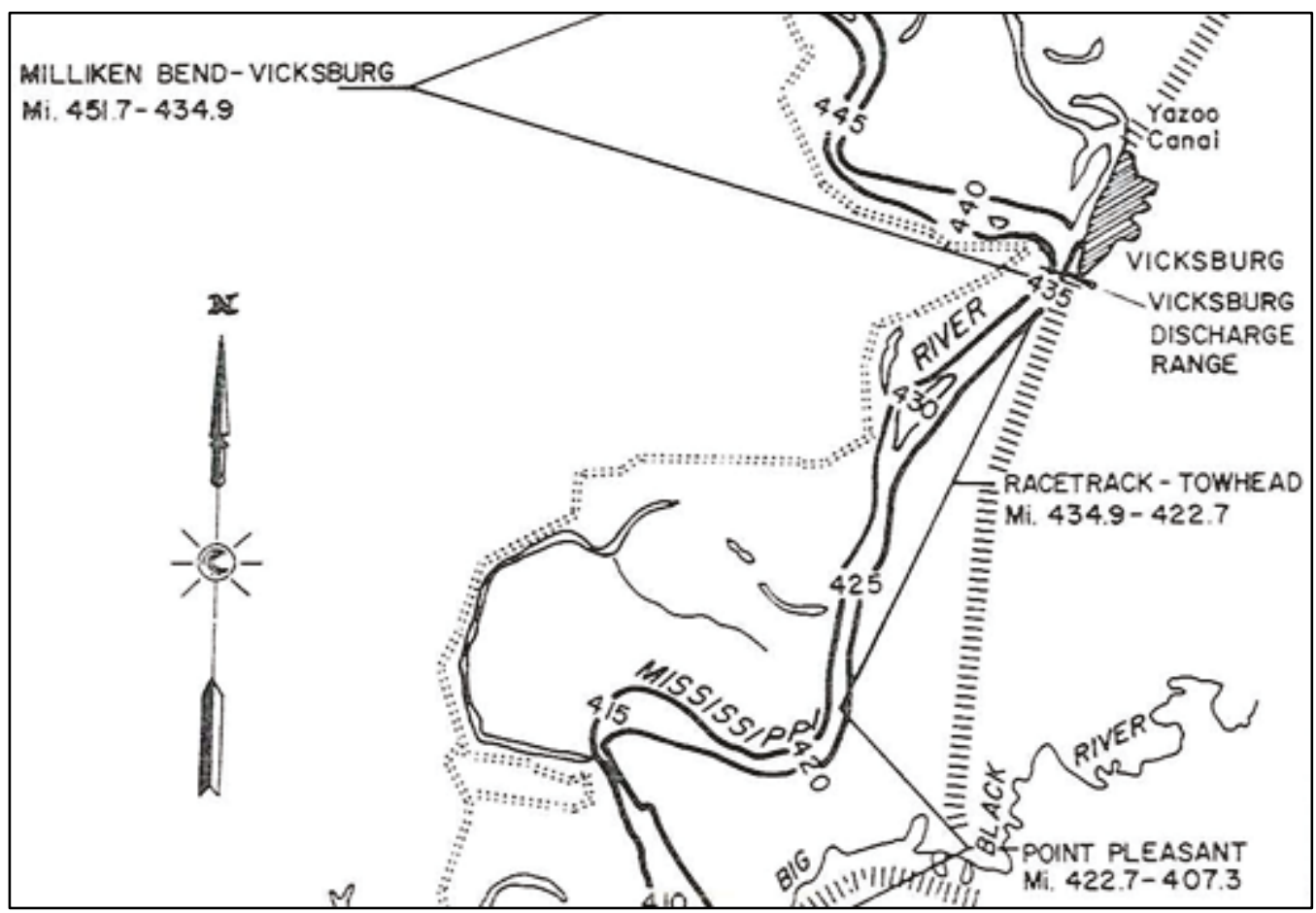

\section{Study objective}

The historical Racetrack Reach was selected as the study reach due to the availability of hydrographic surveys, bed material data, and average sediment size gradations within this reach in the late 1960 s along with the long-term flow measurements at the USGS Vicksburg gage. The objective of this study was to evaluate the variability in model results based on the various options for noncohesive suspended sediment transport functions, noncohesive bed load entrainment functions, and sediment hiding factors within the Adaptive Hydraulics (AdH)/SEDLIB modeling suite. The study uses data collected by the Potamology Program from the 1960s to develop and execute a two-dimensional (2D) model of the Racetrack Reach of the Mississippi River, which could then be updated for future conditions if needed.

The multi-dimensional model presented in this report is a model application developed using the AdH numerical model code, which is 
developed and supported at the U.S. Army Engineer Research and Development Center (ERDC), Coastal and Hydraulics Laboratory (CHL). AdH is linked to SEDLIB, a sediment transport library that is also developed and supported at CHL. The model simulates hydrodynamic and sedimentation processes in the Mississippi River along the Racetrack Reach and adjacent floodplains.

\section{Approach of the study}

The approach for this study is as follows:

- Assemble and analyze all data pertinent to numerical model. development. (e.g., bathymetry, infrastructure, roughness characteristics, boundary condition data).

- Develop the computational mesh.

- Calibrate hydrodynamics.

- Complete sediment transport simulations using various transport algorithms.

The results of these tasks are contained in this report. Chapter 2 details the hydrodynamic and sediment models utilized in this study along with some of the important features of each. Chapter 3 details the development of the numerical model mesh and boundary conditions. Chapter 4 discusses the model calibration and validation. Chapter 5 discusses the sediment transport results, and Chapter 6 presents the conclusions. 


\section{Model Description}

\section{Adaptive Hydraulics (AdH) and SEDLIB}

For this study, AdH is applied in 2D depth-averaged mode on the ERDC High Performance Computer, Topaz. The adaptive aspect of AdH is its ability to dynamically refine the mesh in areas where more resolution is needed at certain times due to changes in the flow and/or transport conditions. AdH can simulate the transport of conservative constituents as well as sediment transport that is coupled to bed and hydrodynamic influences. The ability of AdH to allow the domain to wet and dry as the river stage changes is important in accurately simulating the Mississippi River as it can possess vastly different flow rates and water levels.

SEDLIB is a sediment transport library developed at ERDC (Brown 2012a). It is capable of solving problems consisting of multiple grain sizes, cohesive and noncohesive sediment types, and multiple bed layers. It calculates erosion and deposition processes simultaneously and simulates such bed processes as armoring, consolidation, and discrete depositional strata evolution.

The SEDLIB library system is designed to link to any appropriate hydrodynamic code. The hydrodynamic code must be capable of performing advection diffusion calculations for a constituent. SEDLIB interacts with the parent code by providing sources and sinks to the advection diffusion solver in the parent code. The solver is then used to calculate both bedload and suspended load transport, for each grain class. The sources and sinks are passed to the parent code via an explicit bed sediment flux for each grain class.

This tool has been developed at CHL and has been used to model sediment transport in such varied environments as the Mississippi River, tidal conditions in southern California, and vessel traffic in the Houston Ship Channel.

The AdH/SEDLIB sediment model contributes several capabilities to this analysis, including the following:

- The 2D module of AdH was utilized for this study, but it possesses quasi-three-dimensional (3D) flow and transport formulations, which 
use analytical and semi-empirical methods to approximate the $3 \mathrm{D}$ character of the flow and sediment transport phenomena while solving the 2D depth averaged shallow water equations (Brown 2008, 2012b).

- The model has the ability to present the effects of helical flow through a river bendway on the suspended and bedload sediment transport by utilizing the bendway vorticity transport algorithm given by Bernard (1992).

- The SEDLIB module is equipped to simulate multi-grain class suspended load and bedload sediment transport phenomena. It is also equipped to handle generalized multi-grain class bed processes, including armoring, sorting, erosion to a solid boundary, and the storage of discrete depositional strata.

- The unstructured model mesh employed by AdH permits very high resolution in areas of interest and high-fidelity resolution of shoreline geometry. 


\section{Model Development}

\section{Model mesh development}

The historical bathymetric survey data held by MVK from the 1960s through the 1980 s was collected, organized, and converted by ERDC for the Racetrack Reach of the Mississippi River (approximate RMs 435 to 424). The survey hard copy plan sheets (see the Appendix) were scanned, georeferenced, and digitized to incorporate the bathymetry data into the AdH mesh. Conversions of vertical and horizontal datums were performed to obtain a consistent Graphic Information Systems data set. Any substrate information, including sediment measurements, collected during this time period was organized.

The model mesh boundary (Figure 3-1. Model limits) extends from approximately 10 miles upstream of the I-20 bridge in Vicksburg, MS, to 24 miles downstream of the bridge for a total of approximately 34 RMs. The mesh extends east and west to the elevation of highest flood for the period of record or to the levees, and into the Yazoo River flood plain to Highway 465. The mesh elevation data were specified using 1965 hydrographic cross-sectional survey data. The mesh domain includes 137,166 acres, over 41,000 elements, and approximately 21,000 nodes. The mesh resolution (Figure 3-2) is set such that the river channel has 50-meter (m) spacing on average, the element size increases toward the mesh boundaries and decreases in the river. The horizontal coordinate system used for this application is Mississippi Transverse Mercator (MSTM), in meters. The vertical coordinate system is National Geodetic Vertical Datum of 1929 (NGVD 29), in meters. 
Figure 3-1. Model limits.

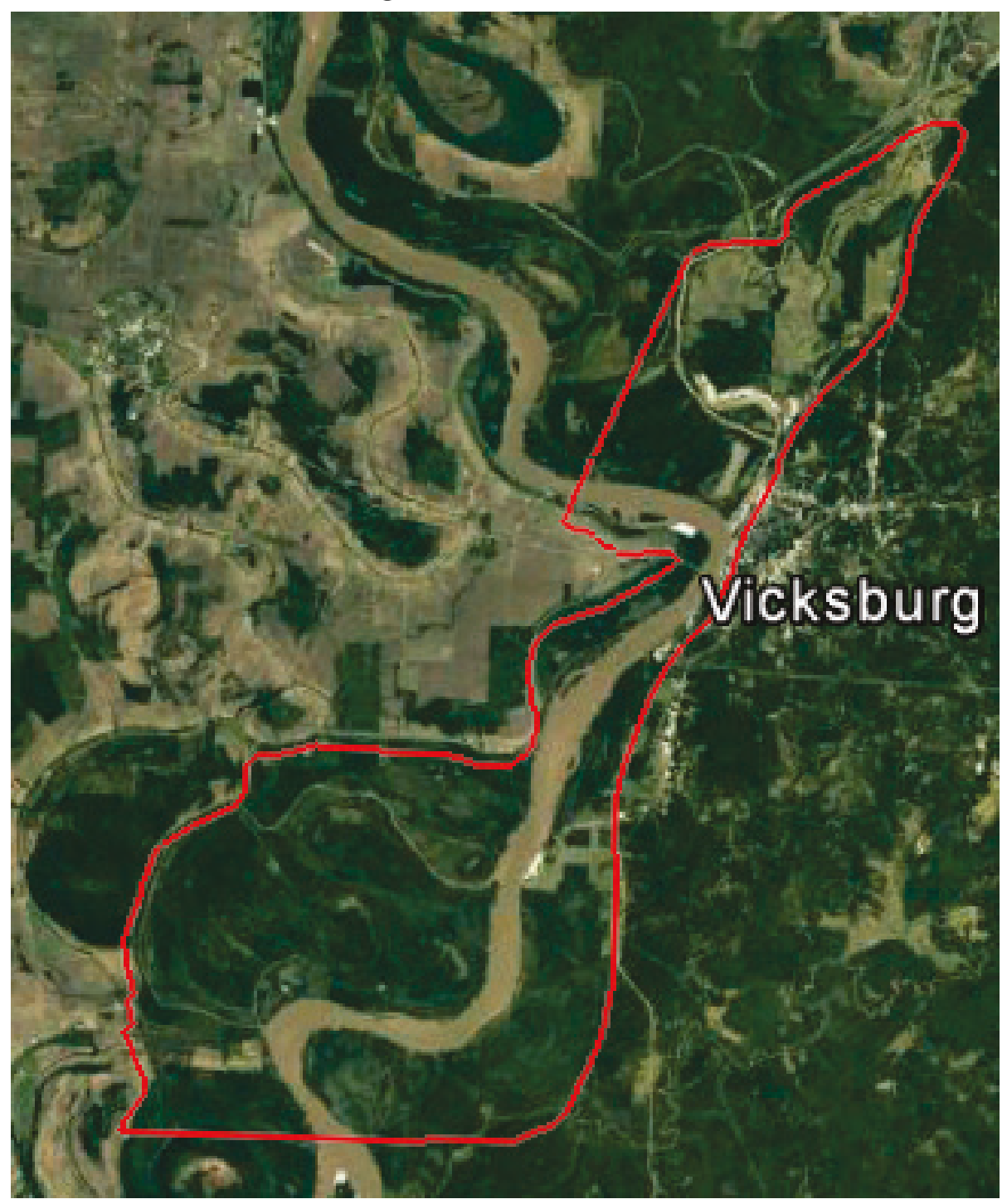


Figure 3-2. Model mesh of channel and overbank.

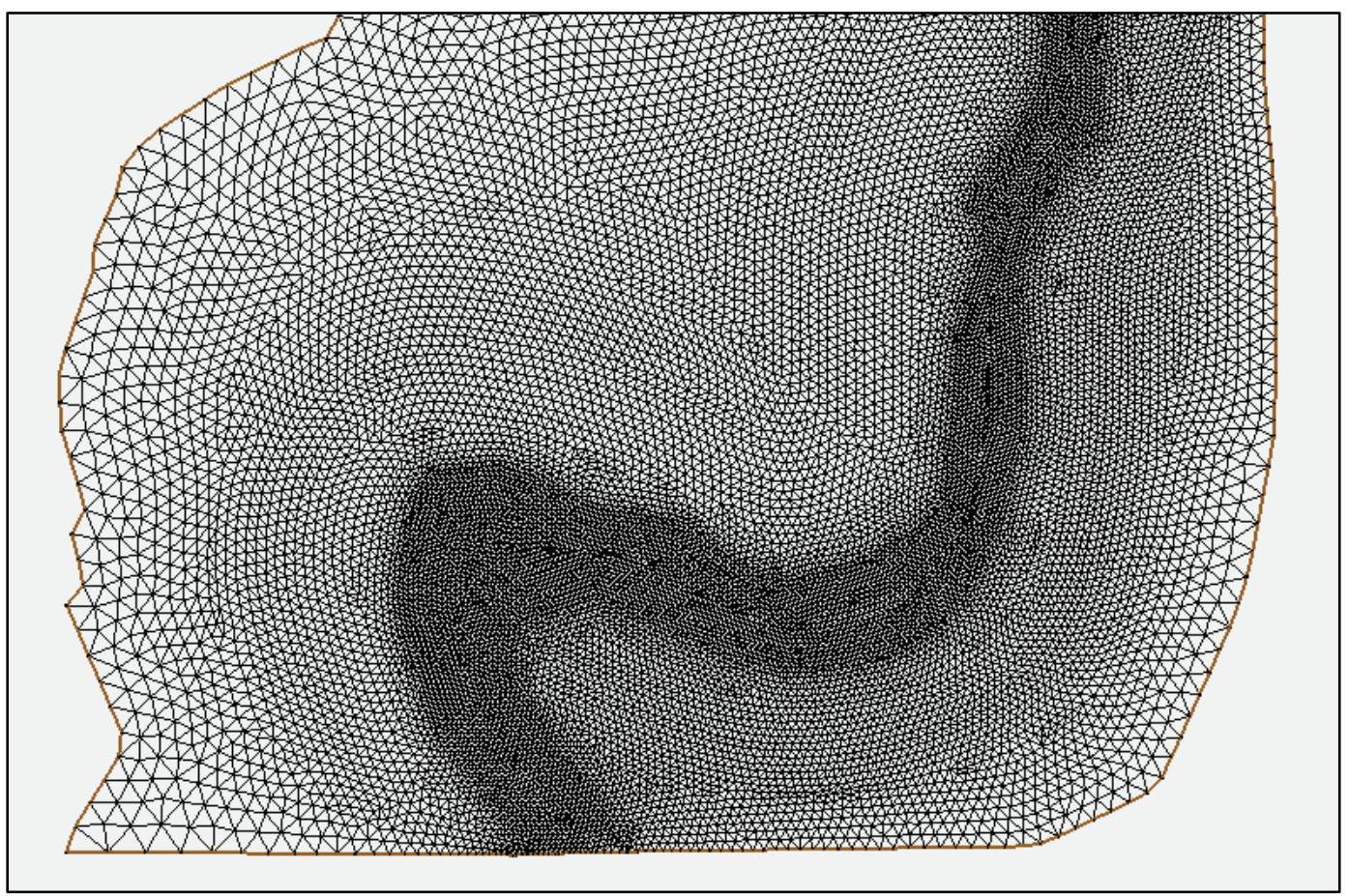

A list of dikes in the Racetrack Reach was formulated for 1968, 1976, 1978, and 1996. In 1968, the first dike was constructed in this reach by placing old car bodies in the river. The car-body dike was identified as being present during the simulated time period, but due to the uncertainty in the composition, the dike was not explicitly resolved in the mesh bathymetry. A separate material type was included with a higher frictional value to incorporate some of the effects of the car-body dike, but given the uncertainty in the remaining characteristics, additional effort to resolve this feature was not deemed necessary. Due to the limited extent of this feature, minimal impacts are expected in terms of global hydrodynamics and sediment transport due to the presence of this single dike. If this model is used to simulate any events between 1976 and present day, multiple training dikes will need to be incorporated into the mesh. The exact dikes to be included would depend on the time period being simulated and the time of construction for the individual dikes.

\section{Hydrodynamic boundary conditions}

Boundary condition data were obtained from several different sources and checked for accuracy prior to use in the numerical model. For this study, boundary condition data were processed for 1965-1969 so that any or all of this time period could be simulated. 


\section{Tailwater specification}

For the time period simulated in this study, the USACE was operating the Vicksburg, MS, gage. Daily water level measurements were taken at the Vicksburg, MS, gage. The water level observations were used with another historical gage located at St. Joseph, LA. Using the Vicksburg, MS, observations and the St. Joseph, LA, observations, a river slope was calculated. Given the known gage locations, a linear interpolation was performed to obtain the downstream tailwater specified in the numerical model. Figure 3-3 shows the Vicksburg, St. Joseph, and interpolated model boundary water levels for the simulated time period.

Figure 3-3. Gate and interpolated water levels.

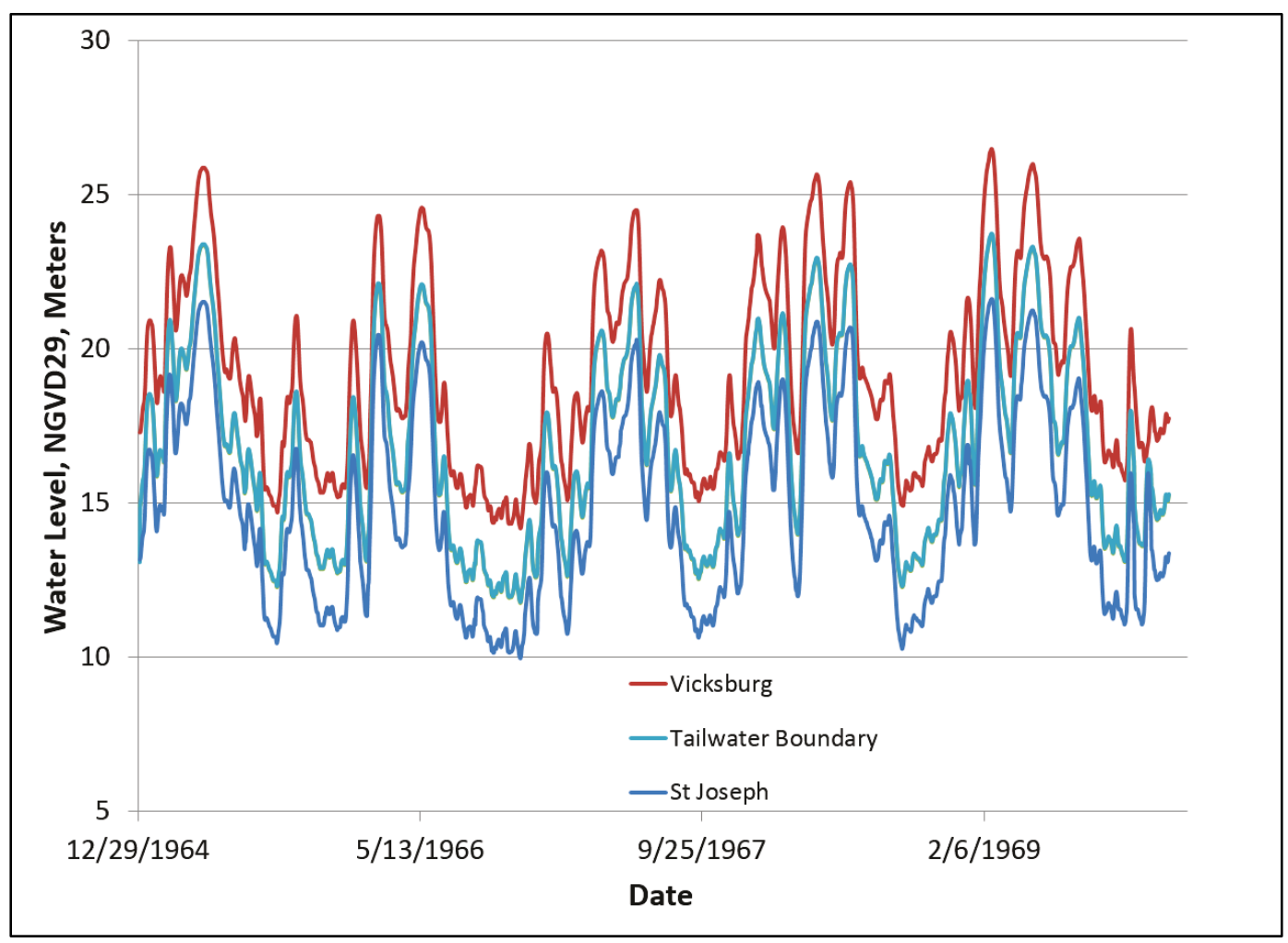

\section{Inflow boundary specification}

The model inflow boundary consists of time-varying inflow values for the Mississippi River. The water level observations at the Vicksburg, MS, gage along with a known stage/discharge relationship provided daily discharge estimates that could be applied in the numerical model. A hydrograph simulation was performed to determine how the model compares to the field over time and under varying flow/tailwater conditions. 


\section{Sediment boundary conditions and bed initialization}

The sediment is modeled in terms of discrete grain classes. The full range of noncohesive classes that are found in the bed material are represented in the model to allow proper sorting of the bed. The simulated grain classes and sizes are given in Table 3-1.

Table 3-1 Sediment classification.

\begin{tabular}{|l|c|c|}
\hline Sediment Class & Abbreviation & Diameter (mm) \\
\hline Very fine sand 2 & VFS2 & 0.074 \\
\hline Very fine sand 1 & VFS1 & 0.104 \\
\hline Fine sand 1 & FS1 & 0.147 \\
\hline Medium sand 3 & MS3 & 0.208 \\
\hline Medium sand 2 & MS2 & 0.295 \\
\hline Medium sand 1 & MS1 & 0.417 \\
\hline Coarse sand 2 & CS2 & 0.589 \\
\hline Coarse sand 1 & CS1 & 0.833 \\
\hline Very coarse sand & VCS & 1.168 \\
\hline Very fine gravel & VFG & 2.362 \\
\hline Fine gravel & FG & 4.669 \\
\hline Medium gravel & MG & 9.525 \\
\hline Coarse gravel 2 & CG 2 & 19.05 \\
\hline Coarse gravel 1 & CG 1 & 23.5 \\
\hline
\end{tabular}

\section{Noncohesive sediment boundary conditions and bed initialization}

The inflowing sediment boundary condition is represented with an equilibrium boundary condition. This boundary condition applies an inflow boundary that is consistent with the transport functions. This boundary condition is used, in lieu of observations, for the following reasons:

- The observed data are not segregated into discrete grain classes: the use of observed data would require an approximation of this partitioning, which introduces significant uncertainty.

- Inconsistencies between observed concentrations and the concentrations calculated by the transport functions can result in significant erosion or deposition of sediment at the inflow boundary. 
- The model upstream of Vicksburg is run with a fixed bed. This allows the model to adjust to any spurious sediment loads introduced at the boundary without influencing the conveyance capacity of the river.

The sediment bed is initialized as follows:

- The initial bed consists of six bed layers.

- The top five bed layers are zero thickness layers: these are used to store depositional layers during the model simulation.

- The initial bed layer thicknesses were specified based on a depth of $10 \mathrm{~m}$. The grain composition of the bed layers for the main channel above Baton Rouge is given in Table 3-2.

- The grain composition of the layers is taken from data collected in the river and is provided in Table 3-2.

Table 3-2. Applied bed sediment distributions for the river channel.

\begin{tabular}{|c|c|c|}
\hline Sediment Layer & Abbreviation & $\begin{array}{c}\text { Bed Sediment } \\
\text { Composition, Ratio }\end{array}$ \\
\hline 1 & VFS2 & 0.0263 \\
\hline 1 & VFS1 & 0.0075 \\
\hline 1 & FS1 & 0.0048 \\
\hline 1 & MS3 & 0.0015 \\
\hline 1 & MS2 & 0.0018 \\
\hline 1 & MS1 & 0.0027 \\
\hline 1 & CS2 & 0.0199 \\
\hline 1 & CS1 & 0.1284 \\
\hline 1 & VCS & 0.3039 \\
\hline 1 & VFG & 0.2982 \\
\hline 1 & FG & 0.1173 \\
\hline 1 & MG & 0.062 \\
\hline 1 & CG 2 & 0.0206 \\
\hline 1 & CG 1 & 0.0051 \\
\hline
\end{tabular}

To finalize the initialization of the bed, the model was simulated with sediment transport for the 1965 hydrograph, without allowing bed elevations to change. This initializes the bed by allowing the grain size distribution to vary spatially in a manner consistent with the local bed shear stresses. This adjusted bed distribution was utilized as the initial bed for all subsequent sediment transport model simulations discussed in this 
report. This initialization of the bed was performed using the WrightParker Suspended Sediment Entrainment Algorithm (Wright and Parker 2004), van Rijn Bedload Entrainment Algorithm (van Rijn 1984), and the Wu Wang Jia Hiding Factor Algorithm (HID) (Wu et al. 2000). 


\section{Calibration and Validation}

\section{Hydrodynamic calibration and validation}

The model roughness parameters were adjusted within an acceptable range as part of the calibration process to obtain the best comparisons to the Vicksburg, MS, water level gage observations. As part of the model calibration, a mesh convergence test was performed using the mesh adaption feature within AdH.

Note that bed shear stress in AdH is not computed by direct application of Manning's equation. Rather, it is computed by an analytic depthintegration of the logarithmic velocity profile so that the computed shear stress is valid for the entire range of depth to roughness ratios. The resulting shear stress is essentially the same as what is obtained from Manning's Equation for flows with roughness to depth ratios in the Manning's Range.

Eddy viscosity is specified as $\mathrm{E}=\mathrm{C} \mathrm{h}$ uf, where $\mathrm{C}$ is a coefficient, $\mathrm{h}$ is the local depth, and $\mathrm{uf}$ is the friction velocity. Values of $\mathrm{C}$ are kept low to avoid excessive numerical diffusion (unitless values of $\mathrm{C}$ are approximately $=$ 0.5): spatial adaption is used to ensure stability and convergence.

\section{Hydrodynamic calibration}

The calibration of the water levels consisted of comparing to the Vicksburg, MS, USGS measurements (Figure 4-1) for the first 9 months of 1965. 
Figure 4-1. River gage location in the model domain.

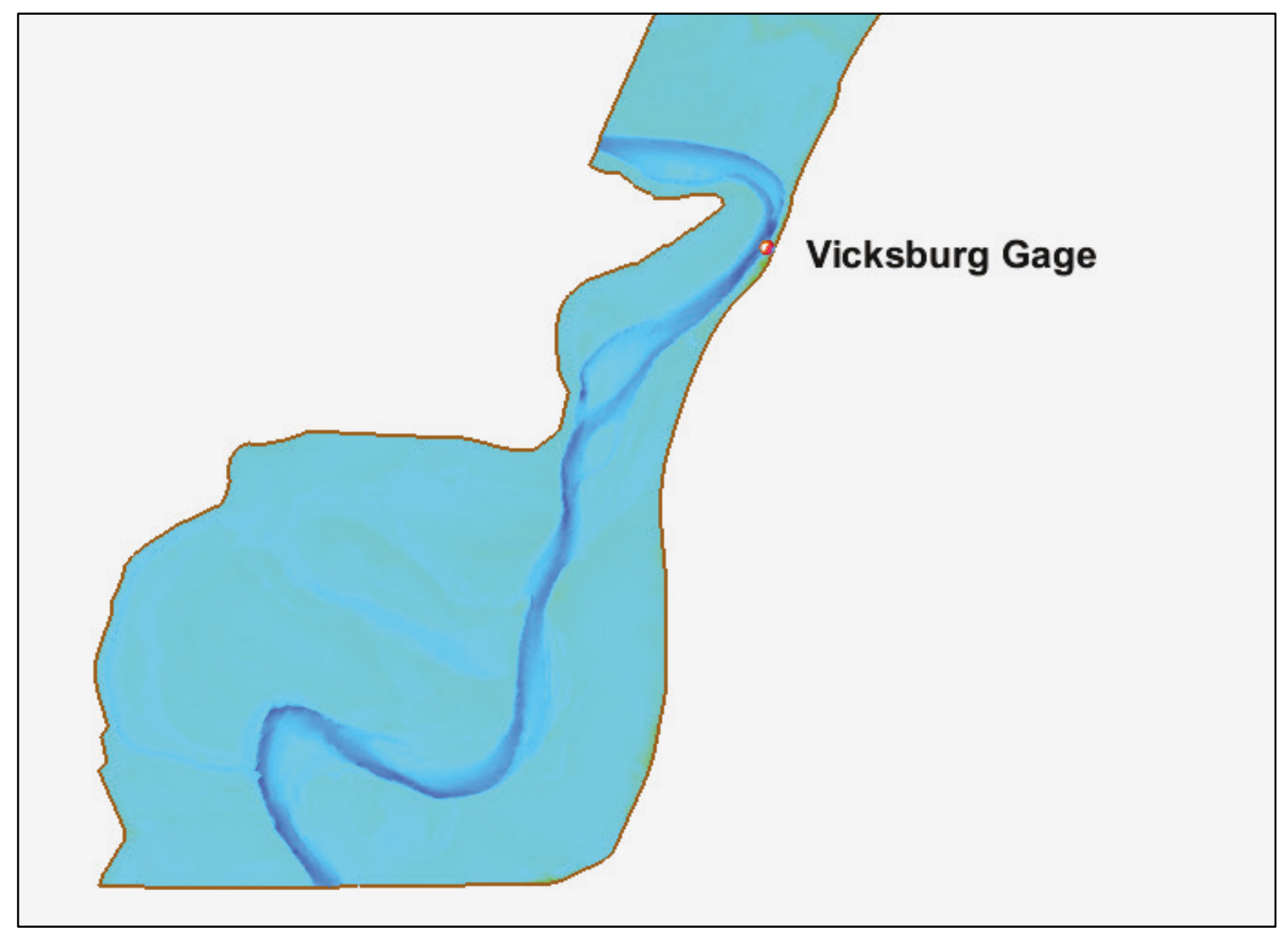


Manning's roughness values were assigned by material types (Figure 4-2).

Figure 4-2. Roughness assigned by material type.

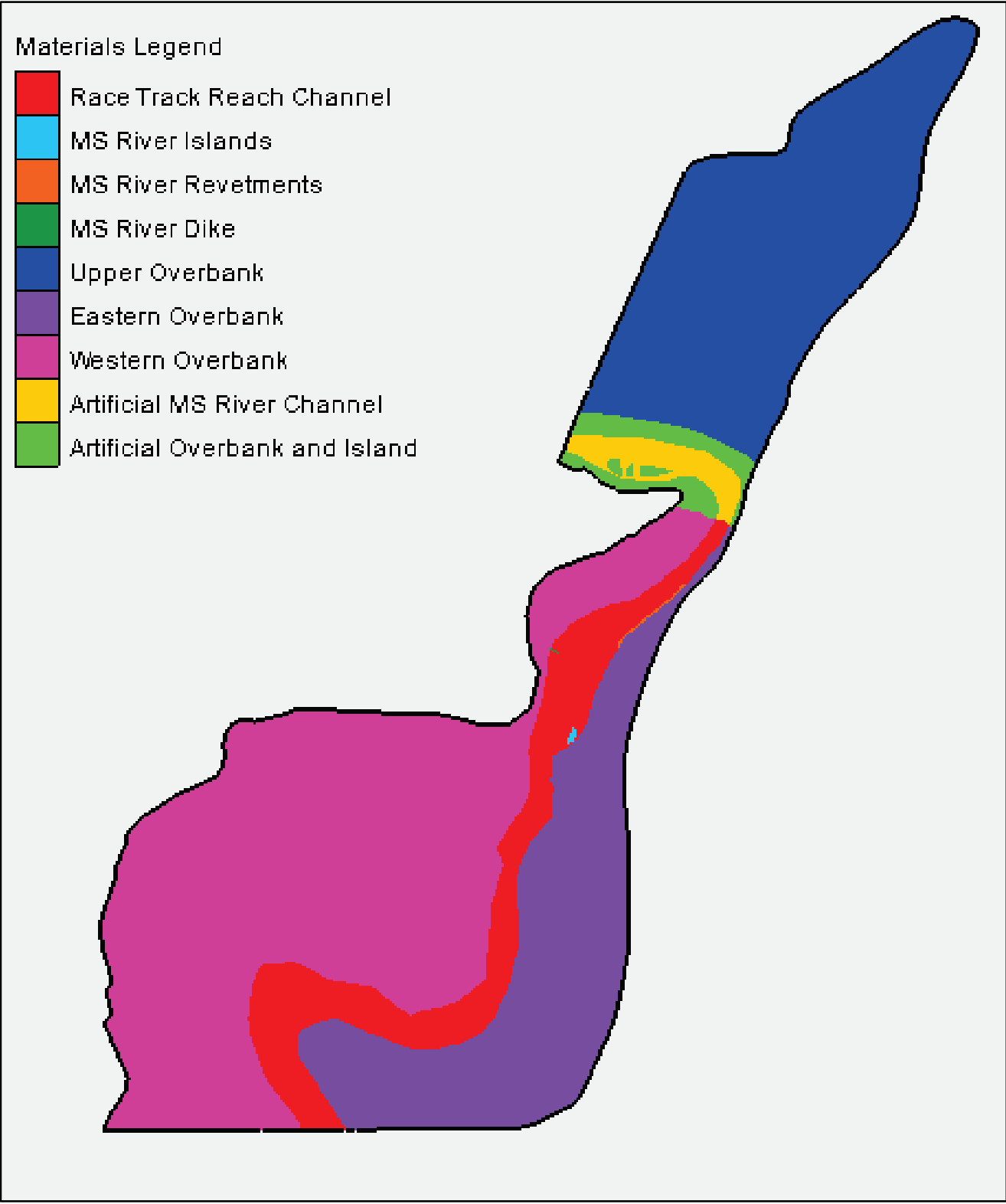

The 1965 hydrograph (Figure 4-3) was simulated to check roughness values to match the water levels at the Vicksburg, MS, gage. The time period of 1 January $1965-15$ August 1965 was selected as these stages and discharges covered a range of flow conditions. Simulations included vorticity and adaption. Sensitivity tests were simulated for eddy viscosity and roughness values. 
Figure 4-3. 1965 hydrograph.

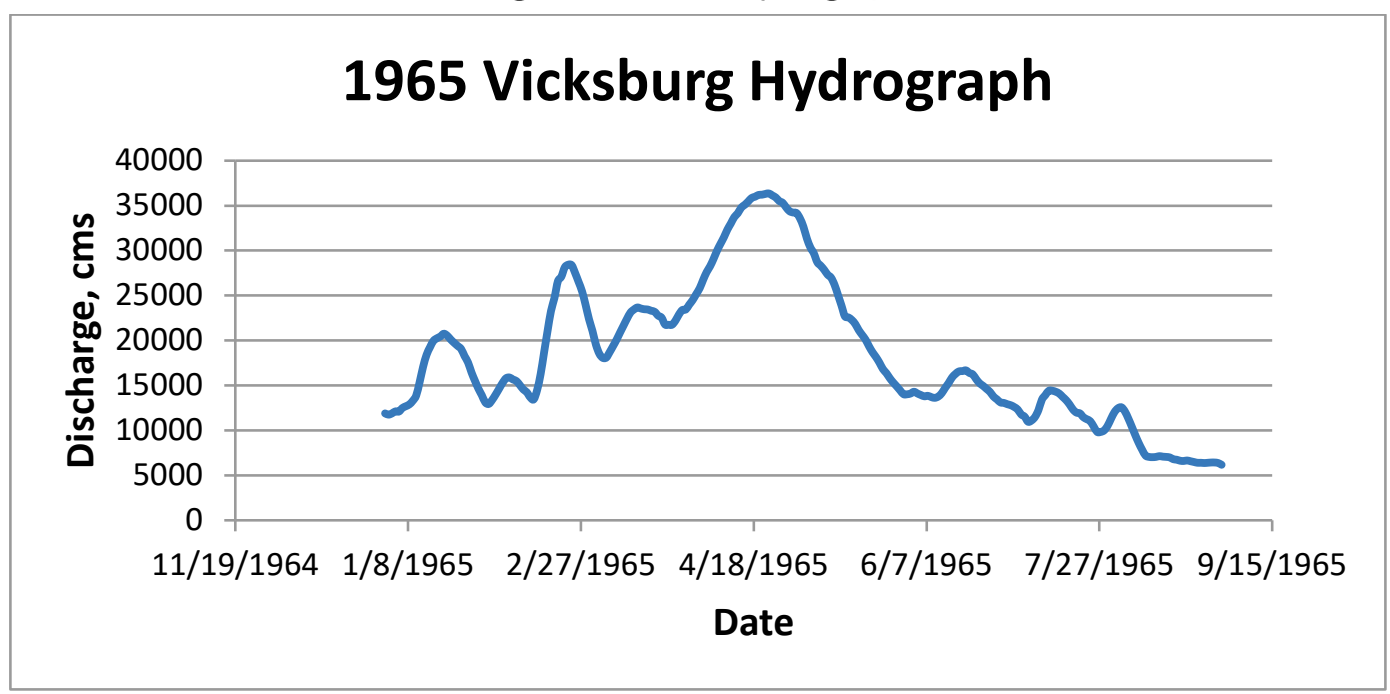

The final calibration Manning's $n$ roughness values (Figure 4-2) are provided in Table 4-1.

Table 4-1. Manning's $n$-values used in the simulations.

\begin{tabular}{|l|c|}
\hline \multicolumn{2}{|c|}{ Manning's $n$-values Used in the Model Simulations. } \\
\hline Area of the mesh & Manning's $n$-value \\
\hline Racetrack reach channel & 0.026 \\
\hline MS River islands & 0.025 \\
\hline MS River revetments & 0.026 \\
\hline MS River dike & 0.035 \\
\hline Lakes in the upper overbank & 0.056 \\
\hline Eastern overbank & 0.056 \\
\hline Western overbank & 0.056 \\
\hline Upstream artificial MS river channel & 0.026 \\
\hline Upstream artificial overbank and islands & 0.056 \\
\hline
\end{tabular}

Using the roughness values in Table 4-1, the 1965 hydrograph (Figure 4-3) was simulated and produced the following WSE plots (Figure 4-4 and Figure 4-5) for the Vicksburg, MS, gage. 
Figure 4-4. 1965 WSE plot: WSE vs. time for Vicksburg.

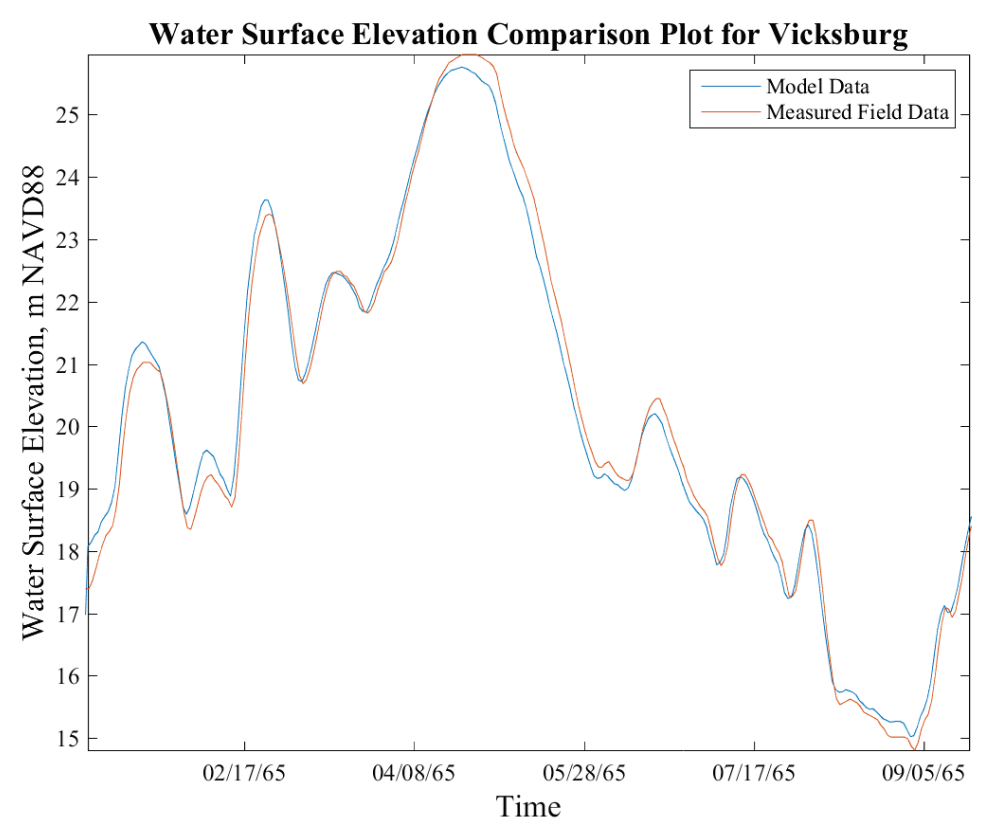

Figure 4-5. 1965 WSE plot: model vs. field for Vicksburg.

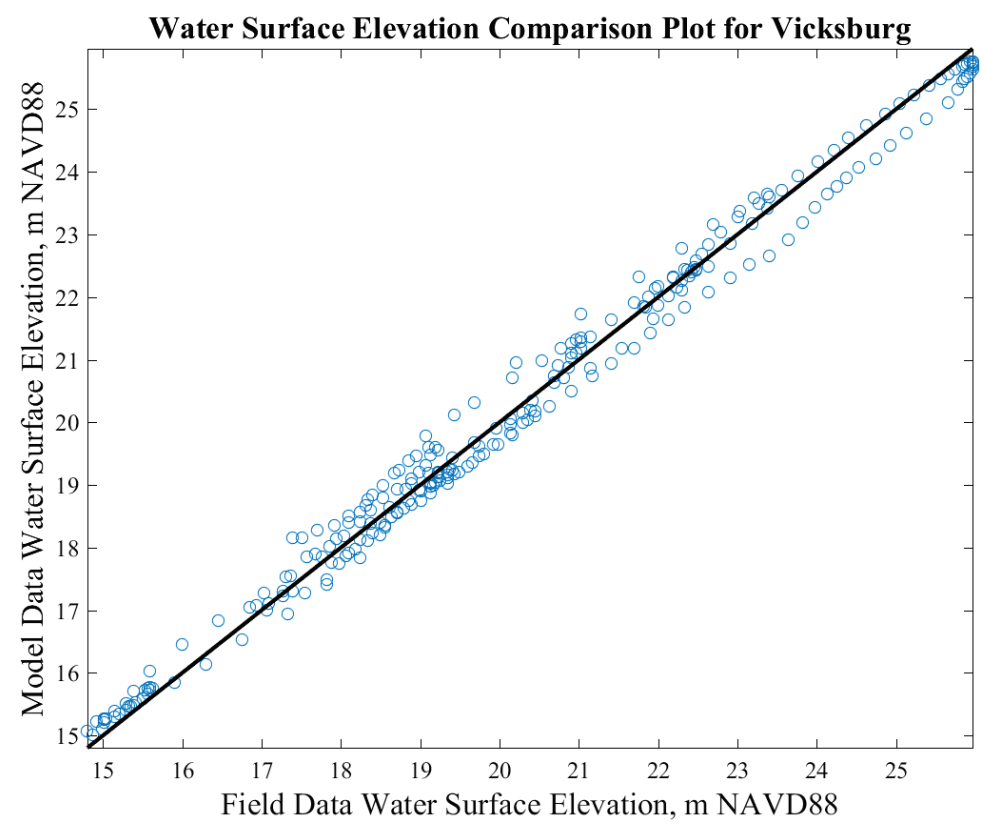

\section{Hydrodynamic validation}

Hydrodynamic validation was performed by comparison of modeled results to observed values of stage for the hydrograph simulation for January 1965 to December of 1969 (Figure 4-6) using the same calibration roughness values as the previously simulated 1965 hydrograph. 
Figure 4-6. 1965-1969 hydrograph.

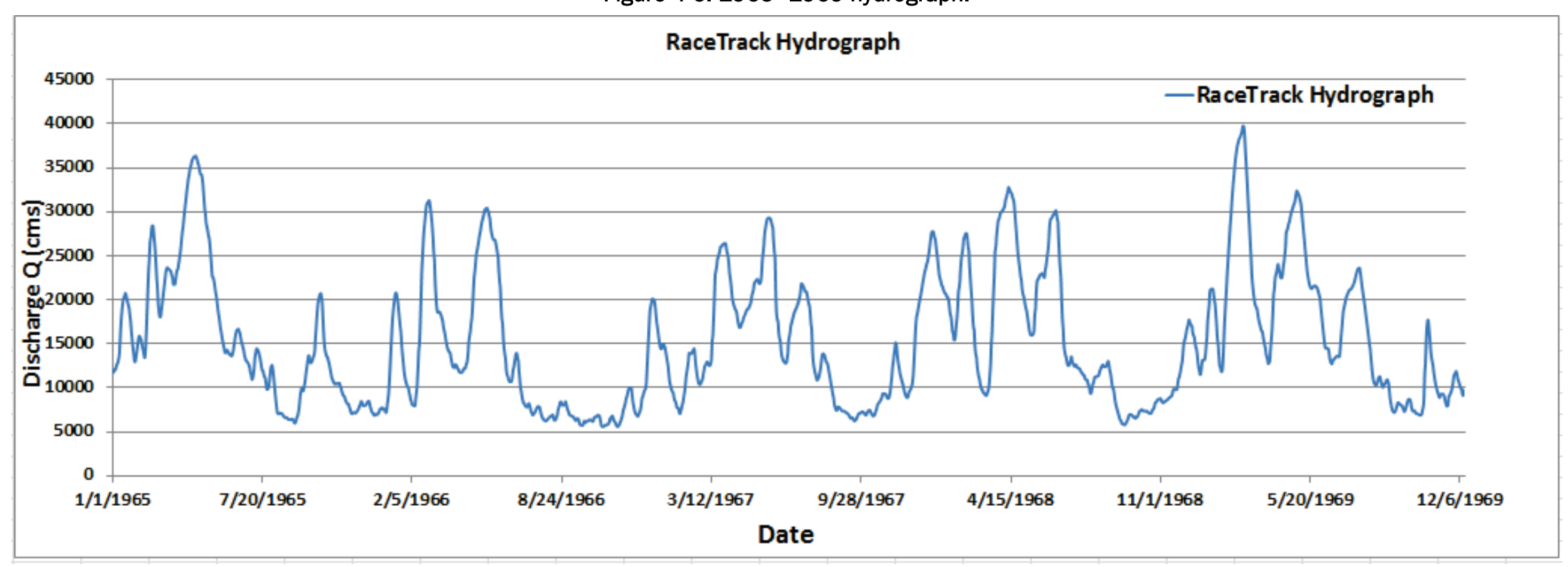


The 1965-1969 hydrograph was simulated and produced the following WSE plots (Figure 4-7 and Figure 4-8) for the USGS Vicksburg, MS, measurements:

Figure 4-7. 1965-1969 WSE plot: WSE vs. time for Vicksburg.

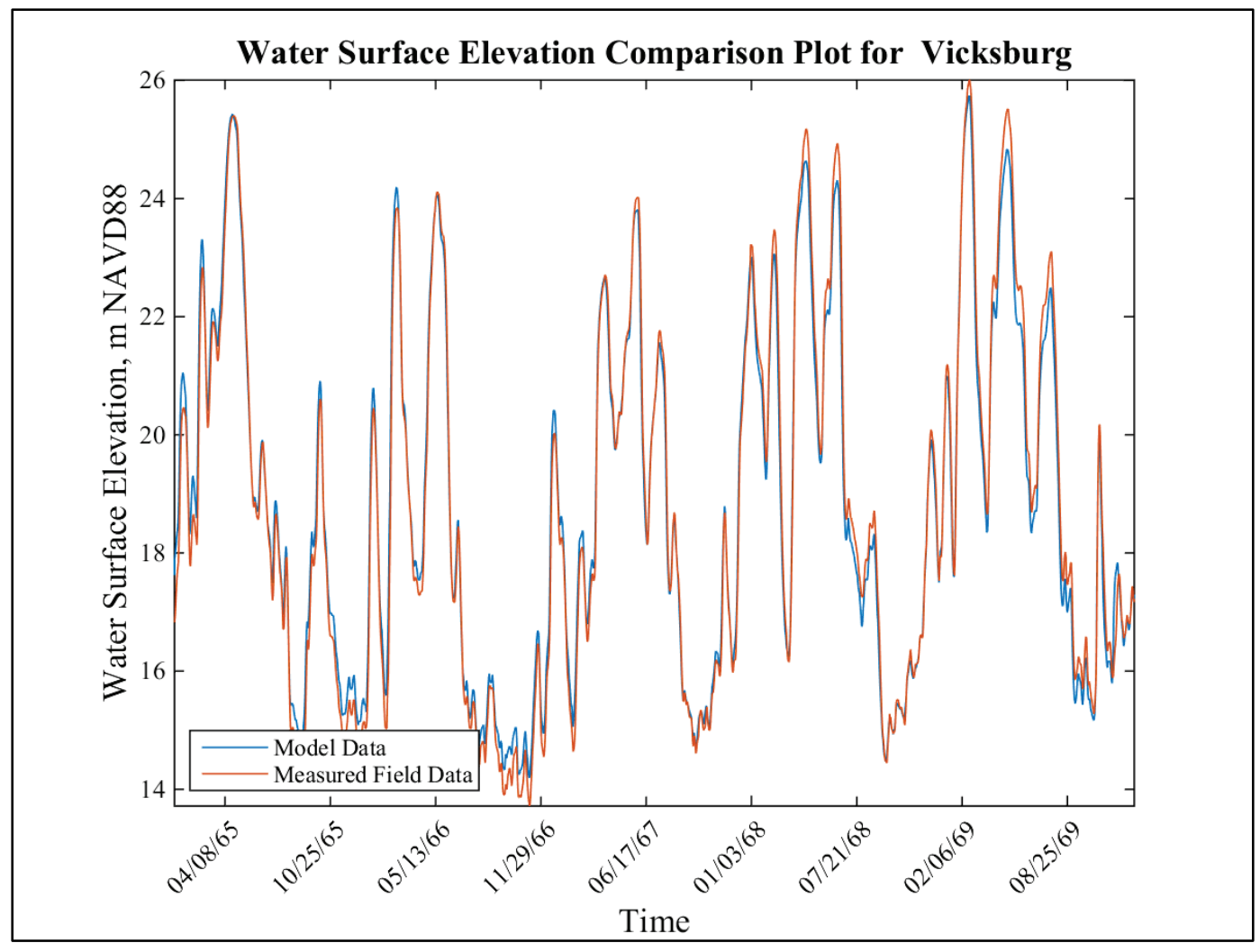


Figure 4-8. 1965-1969 WSE plot: model vs. field for Vicksburg.

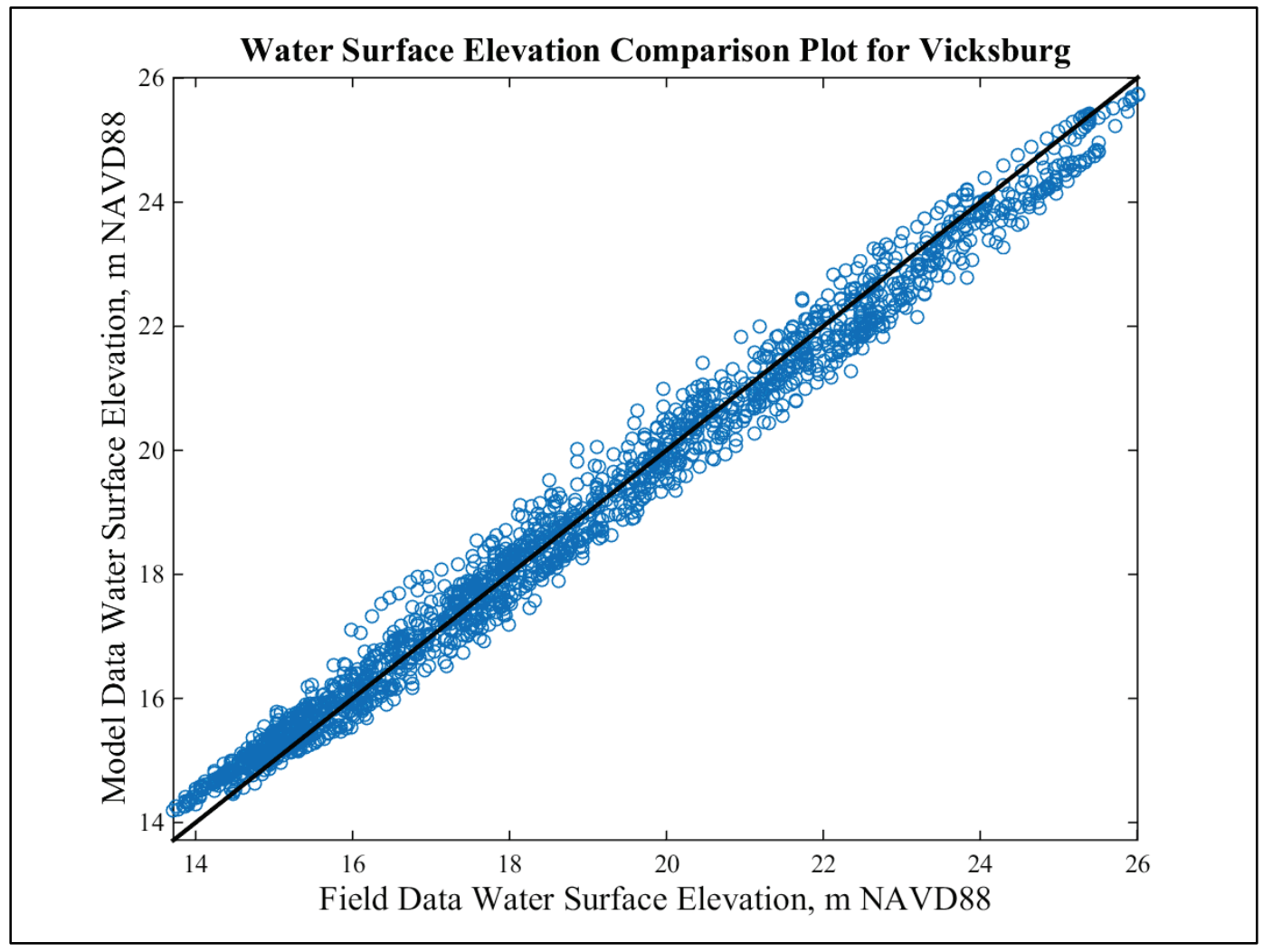

Goodness-of-fit statistics are presented in Table 4-2.

Table 4-2. Goodness-of-fit statistics.

\begin{tabular}{|l|c|}
\hline \multicolumn{2}{|c|}{ Goodness-of-Fit Statistics } \\
\hline Root mean square error & $0.42 \mathrm{~m}$ \\
\hline Nash-Sutcliffe coefficient & 0.98 \\
\hline Willmott coefficient & 1.0 \\
\hline Correlation coefficient & 0.99 \\
\hline
\end{tabular}




\section{Sediment Transport}

The bed gradations and initialization, and the sediment boundary conditions, were determined according to the protocol discussed in Chapter 3. Once these were established, the model was run for the years 1965-1969 (shown in Figure 4-6) and compared to observed data (Figure 4-7). There was no adjustment of coefficients as there were limited data to justify any significant modification of model parameters, and the purpose of this study was to analyze the impact of the various transport options.

\section{Sediment survey data}

The cross-section sediment survey data were obtained from the survey hard-copy plan sheets (see the Appendix). These documents were scanned, georeferenced, and digitized to incorporate the bathymetry into the AdH mesh. There is a missing gap in the 1969 data between RM 418 and RM 423. The primary purpose of the study was to evaluate the noncohesive sediment entrainment, bed-load entrainment, and hiding factor algorithms. Table 5-1 shows eight AdH simulations using different combinations of these algorithms. The noncohesive suspended sediment entrainment algorithm (NSE) uses either the Wright-Parker (1) or Van Rijn (2) equation. The noncohesive bed-load entrainment algorithm (NBE) uses either the Van Rijn (o) or Meyer Peter Mueller with Wong Parker Correction (2). The HID for noncohesive sediments uses either the Eziagaroff (1) or Wu Wang Jia (2) equation. This resulted in a total of eight possible combinations.

The difference between the 1969 and 1965 bathymetry data is presented in Figure 5-1 for RM 435 to RM 425 and Figure 5-2 for RM 425 to 410 . For the comparison, calculated bathymetric changes for the same time period are shown in Figure 5-3 to Figure 5-18, in which the hydrograph utilized was as previously shown in Figure 4-6. The images presented are all contoured the same and divided into the same two reaches, RM 435 to 425 and RM 425 to RM 410. Direct comparisons can be made to the observed field data in Figure 5-1 and Figure 5-2 for each simulation to evaluate the various sediment transport options as detailed in Table 5.1. 
Table 5-1. Racetrack Reach sediment transport runs and algorithms.

\begin{tabular}{|c|c|c|c|}
\hline \multicolumn{5}{|c|}{ Sediment Transport Algorithm's Racetrack Reach } \\
\hline Run \# & NSE & NBE & HID \\
\hline 1 & 1 & 0 & 2 \\
\hline 2 & 2 & 2 & 1 \\
\hline 3 & 1 & 0 & 1 \\
\hline 4 & 1 & 2 & 1 \\
\hline 5 & 1 & 2 & 2 \\
\hline 6 & 2 & 0 & 2 \\
\hline 7 & 2 & 2 & 2 \\
\hline 8 & 2 & 0 & 1 \\
\hline $\begin{array}{l}\text { NSE = Sediment entrainment algorithm } \\
\text { NSE = 1 Wright-Parker } \\
\text { NSE = 2 Van Rijn }\end{array}$ \\
$\begin{array}{l}\text { NBE = Bedload entrainment algorithm } \\
\text { NBE = 0 Van Rijn } \\
\text { NBE = 2 Meyer Peter Mueller with Wong Parker Correction }\end{array}$ \\
$\begin{array}{l}\text { HID = Hiding factor algorithm } \\
\text { HID = 1 Eziagaroff } \\
\text { HID = 2 Wu Wang Jia }\end{array}$ \\
\hline 5
\end{tabular}

All modeled scenarios possess the same general pattern of erosion/deposition with the primary difference in scenarios being the magnitude of erosion/deposition. The Wright-Parker sediment entrainment function resulted in significantly larger erosion/deposition amounts as compared to the Van Rijn sediment entrainment function. The Meyer Peter Mueller with Wong Parker Correction bed-load entrainment function resulted in significantly larger erosion/deposition amounts as compared to the Van Rijn bed-load entrainment function. The hiding factor choice had minimal influence on the sediment transport results. 
Figure 5-1. 1969-1965 observed bed displacement, RM 435 to RM 425.

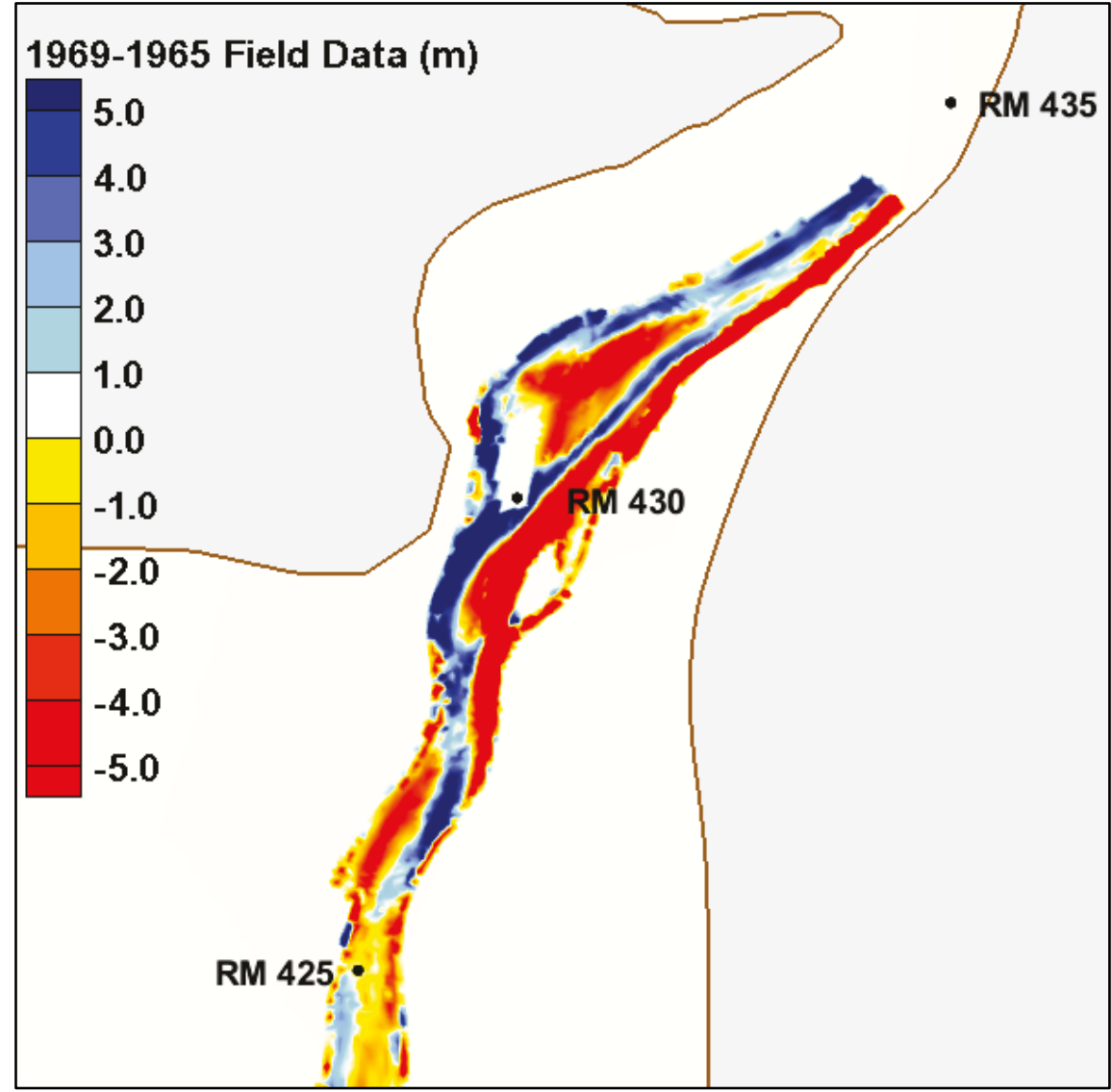

Figure 5-2. 1969-1965 observed bed displacement, RM 425 to RM 410.

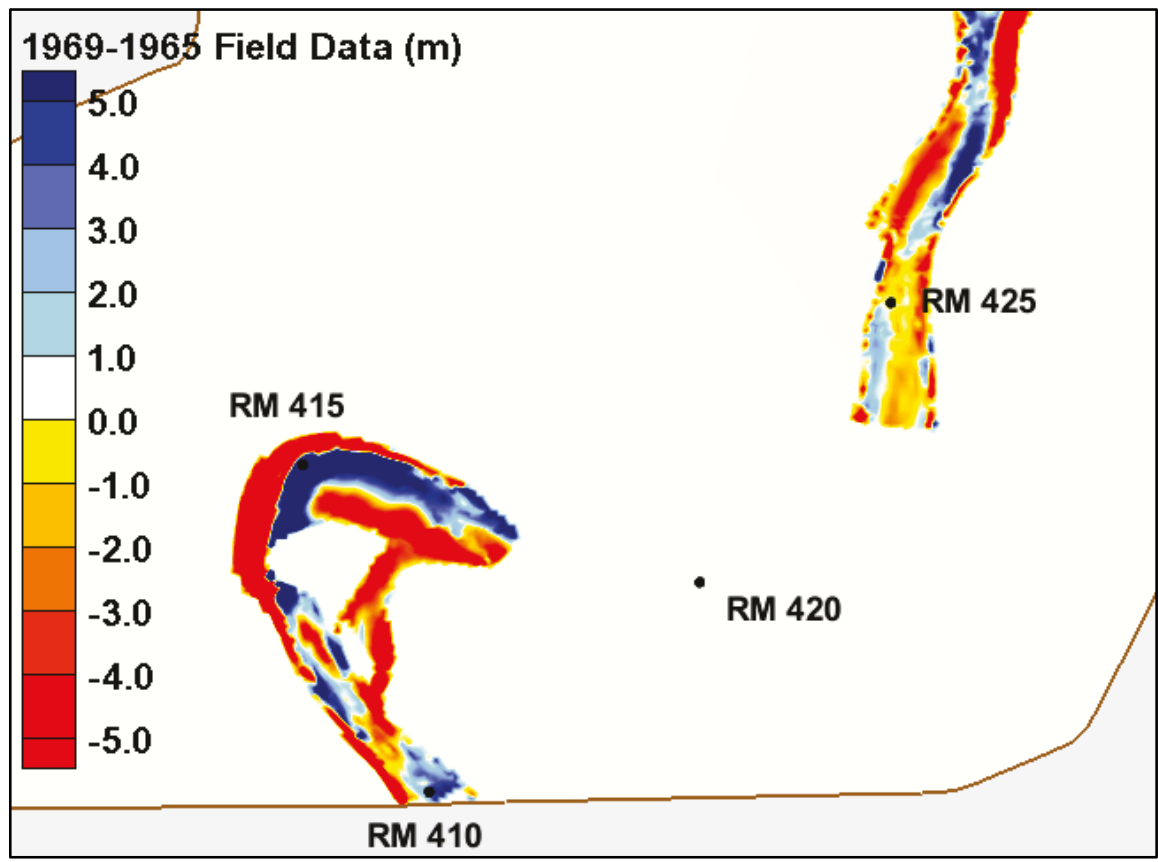


Figure 5-3. 1969-1965 Model Run 1 bed displacement, RM 435 to RM 425.

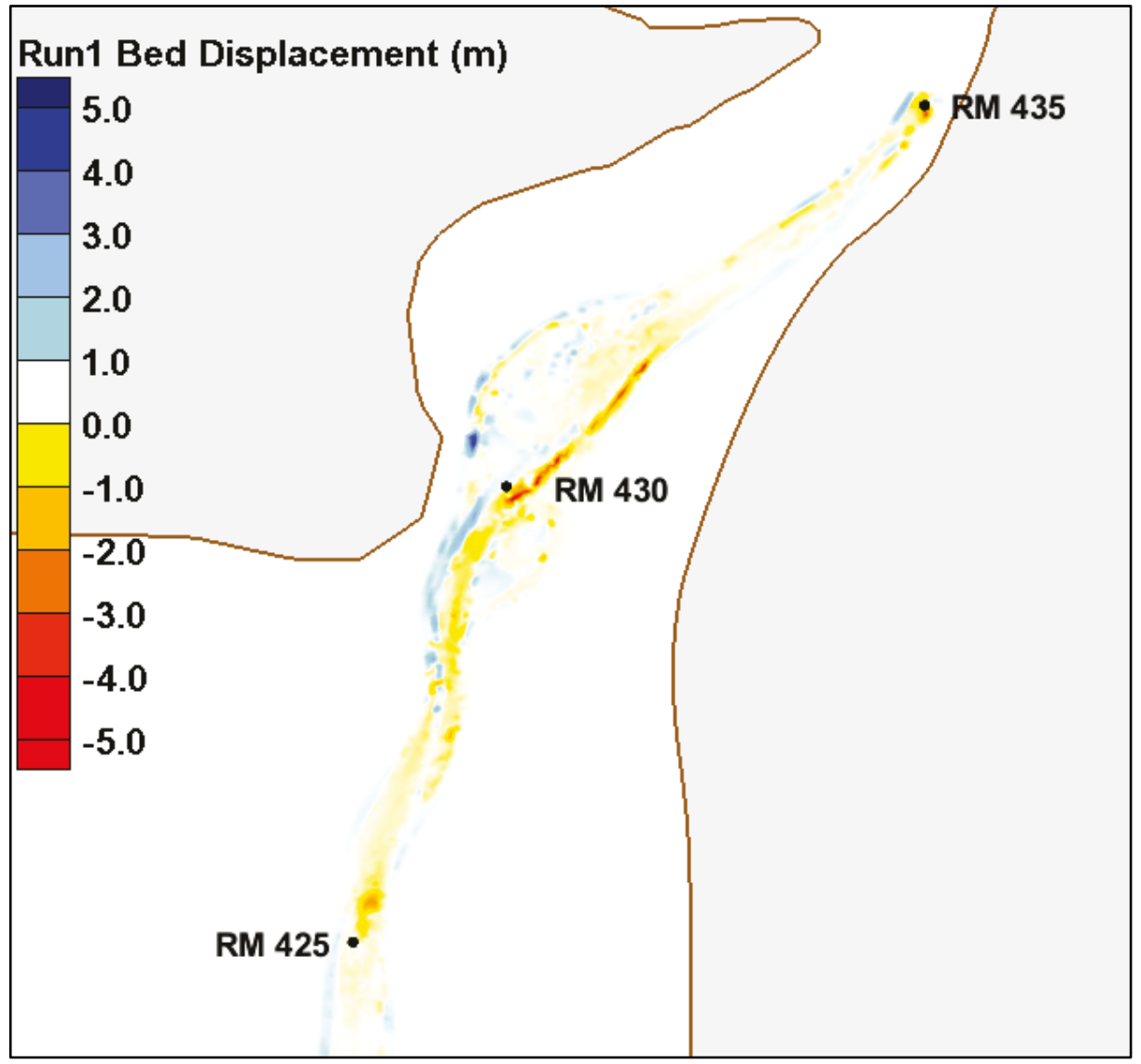

Figure 5-4. 1969-1965 Model Run 1 bed displacement, RM 425 to RM 410.

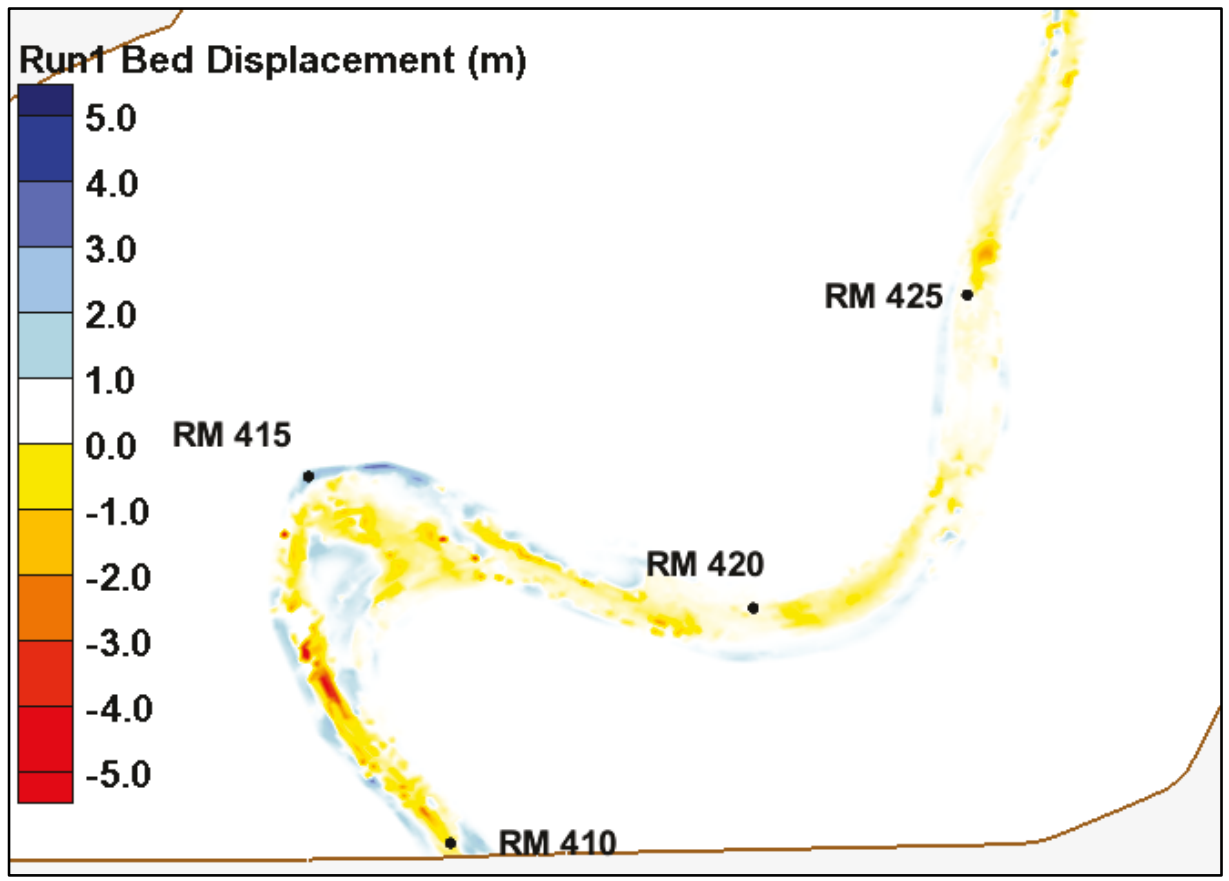


Figure 5-5. 1969-1965 Model Run 2 bed displacement, RM 435 to RM 425.

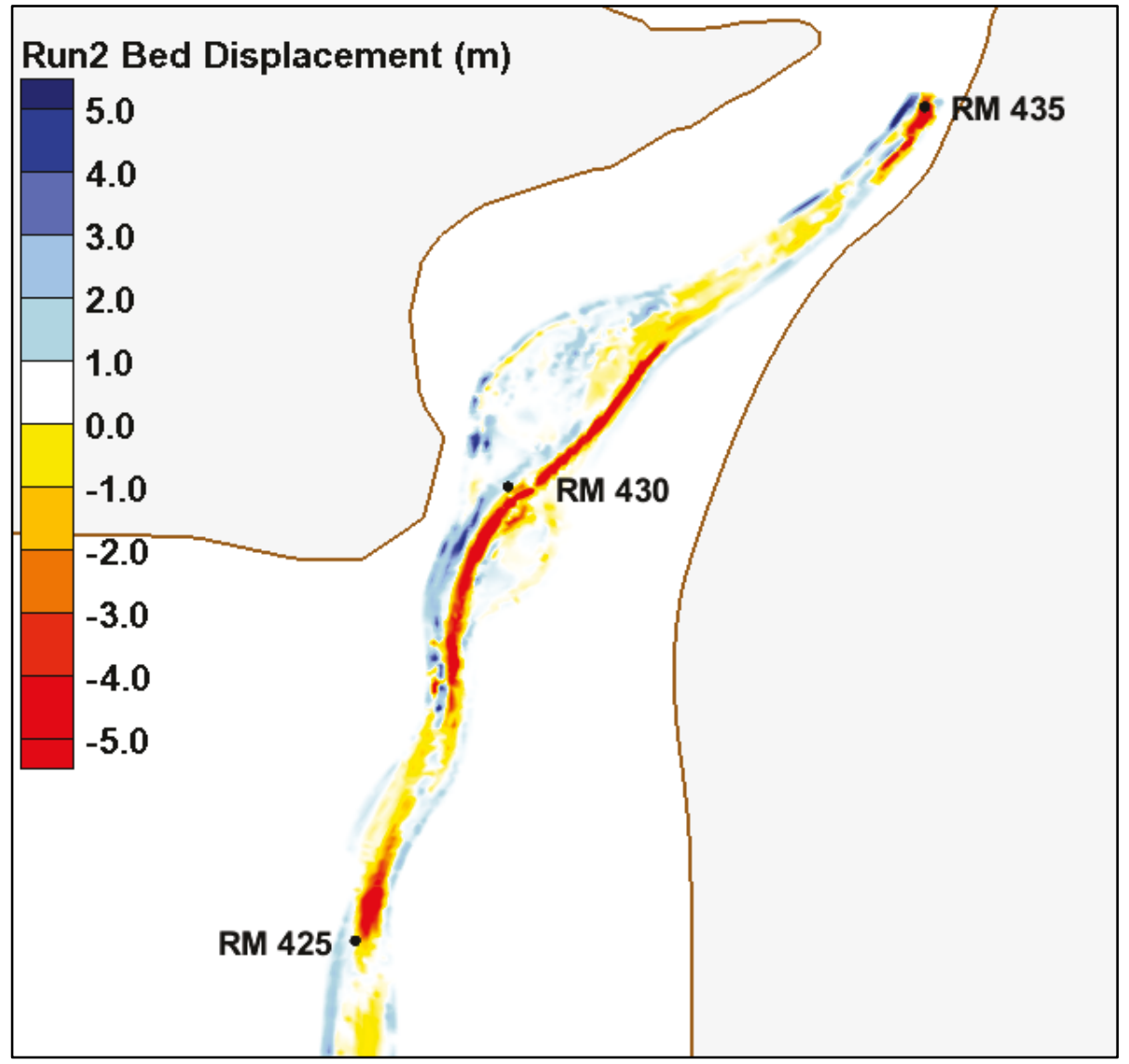

Figure 5-6. 1969-1965 Model Run 2 bed displacement, RM 425 to RM 410.

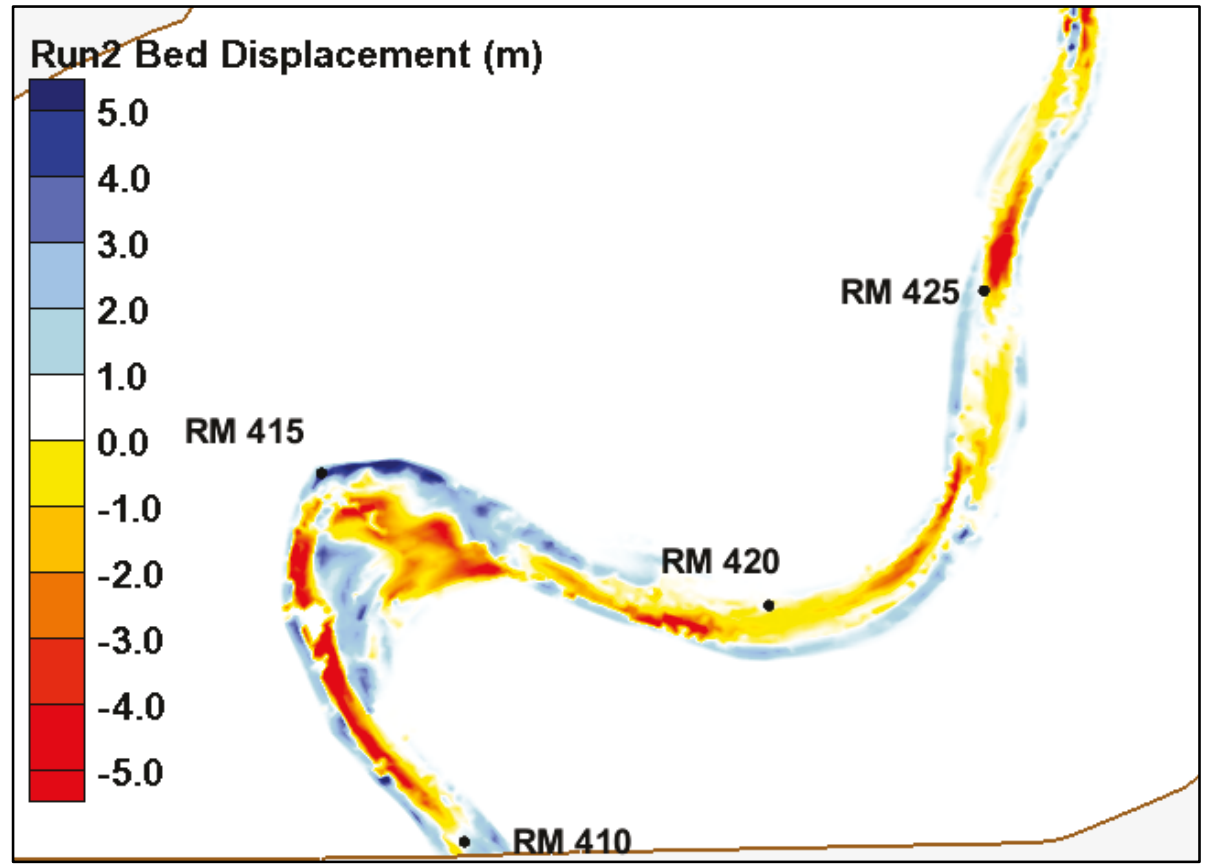


Figure 5-7. 1969-1965 Model Run 3 bed displacement, RM 435 to RM 425.

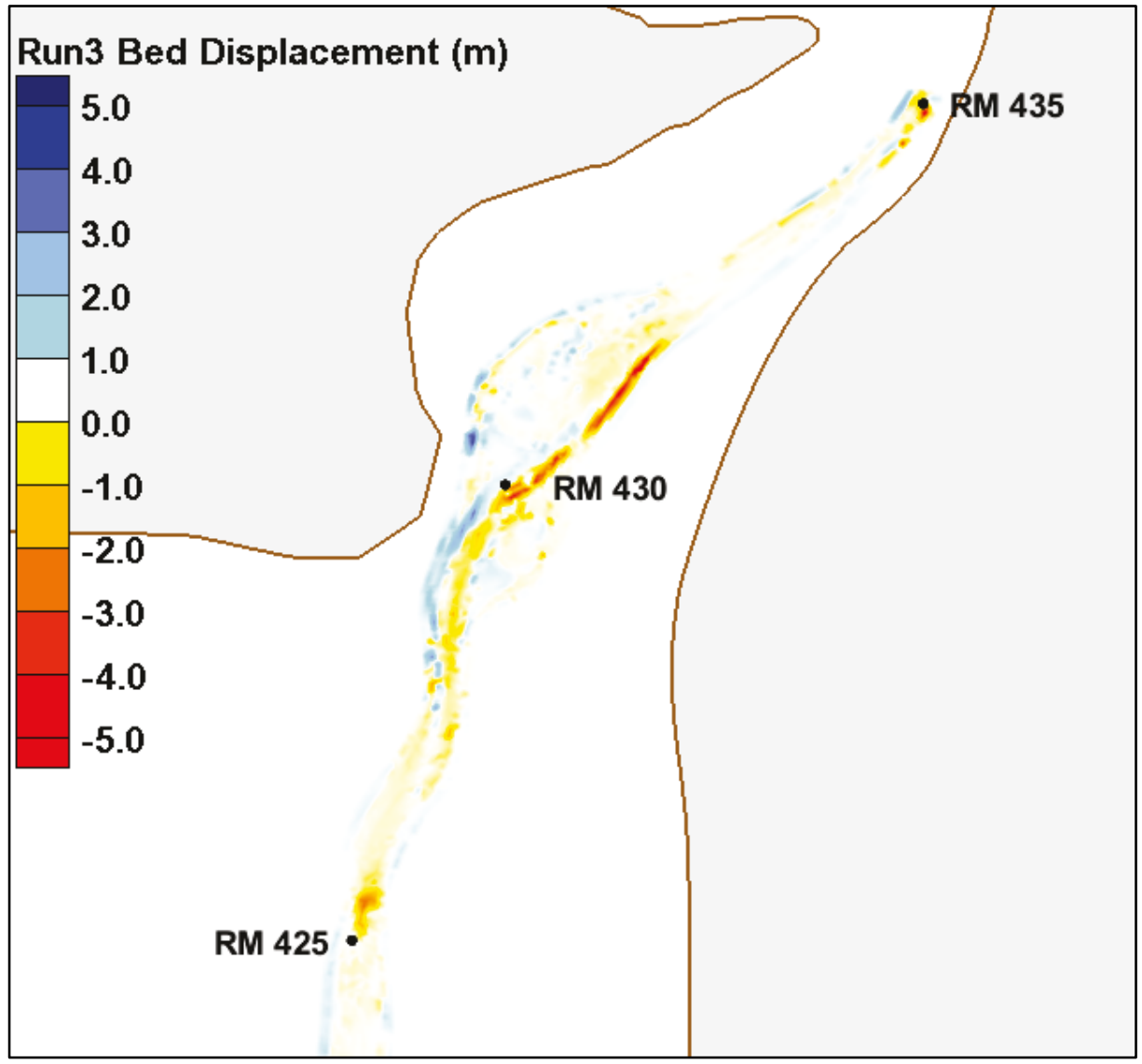

Figure 5-8. 1969-1965 Model Run 3 bed displacement, RM 425 to RM 410.

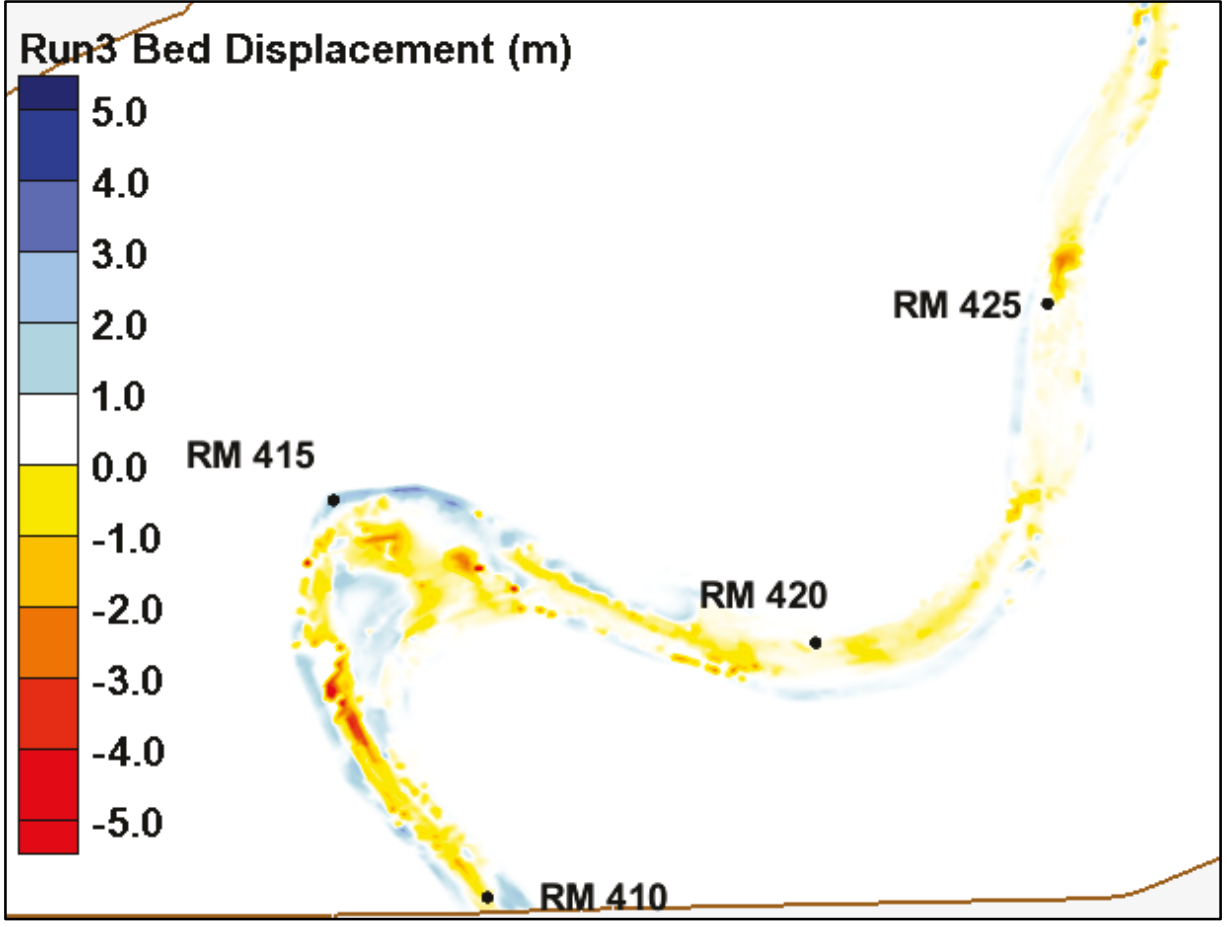


Figure 5-9. 1969-1965 Model Run 4 bed displacement, RM 435 to RM 425.

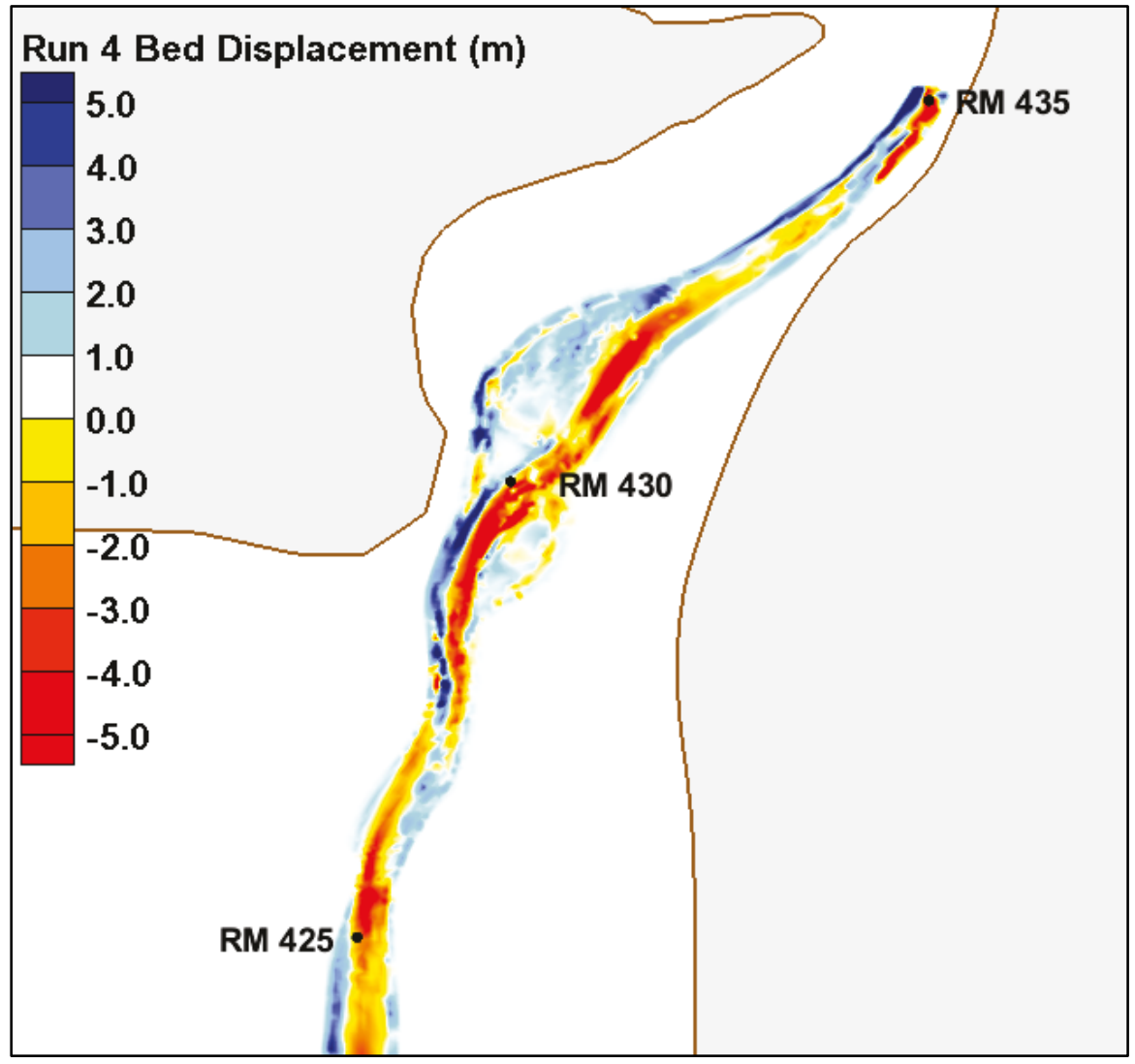

Figure 5-10. 1969-1965 Model Run 4 bed displacement, RM 425 to RM 410.

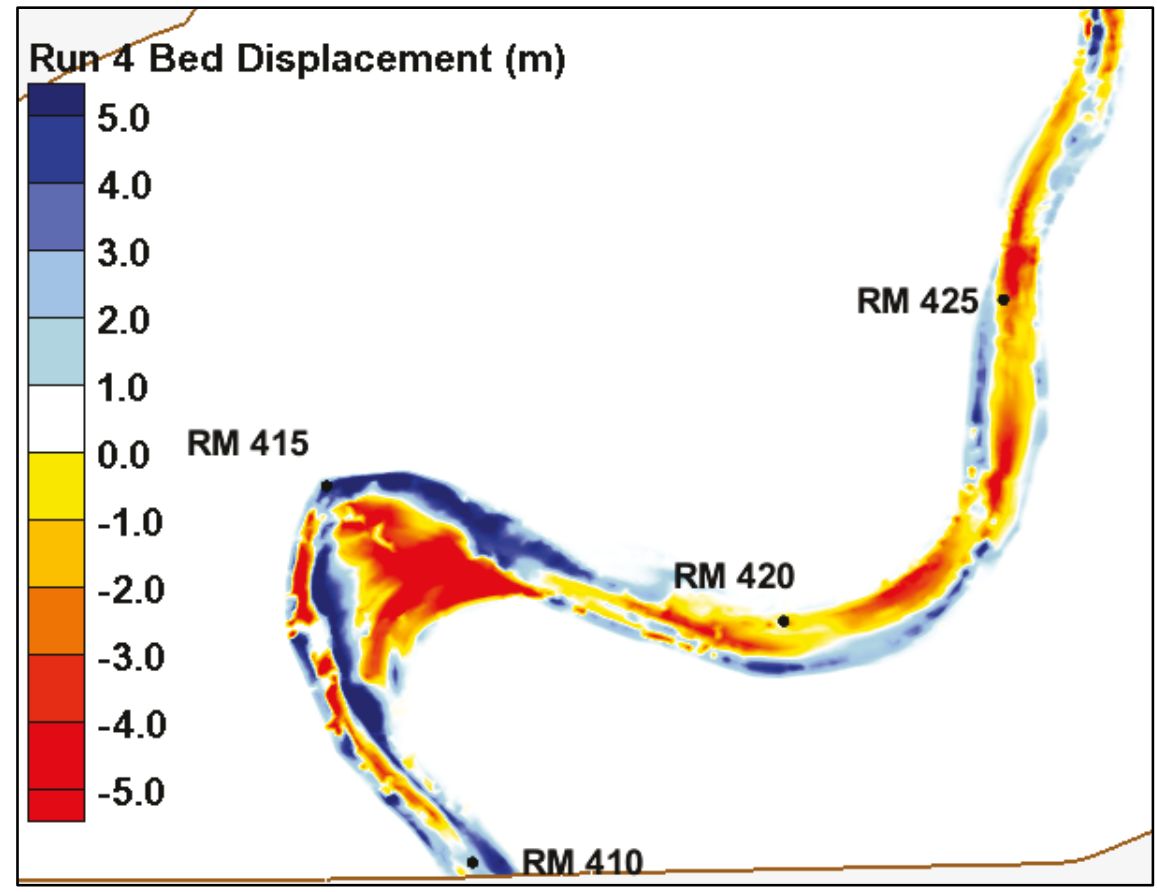


Figure 5-11. 1969-1965 Model Run 5 bed displacement, RM 435 to RM 425.

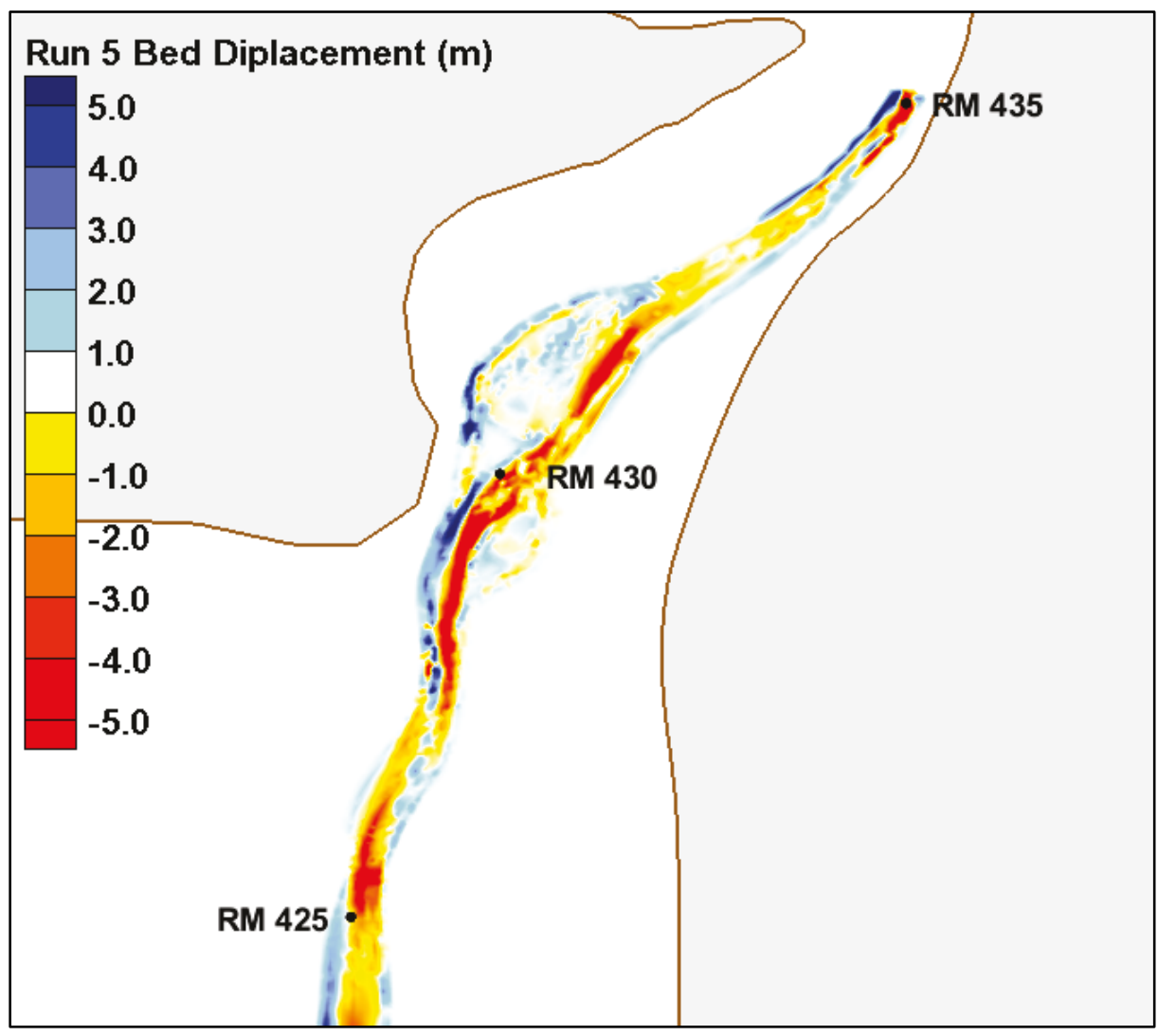

Figure 5-12. 1969-1965 Model Run 5 bed displacement, RM 425 to RM 410.

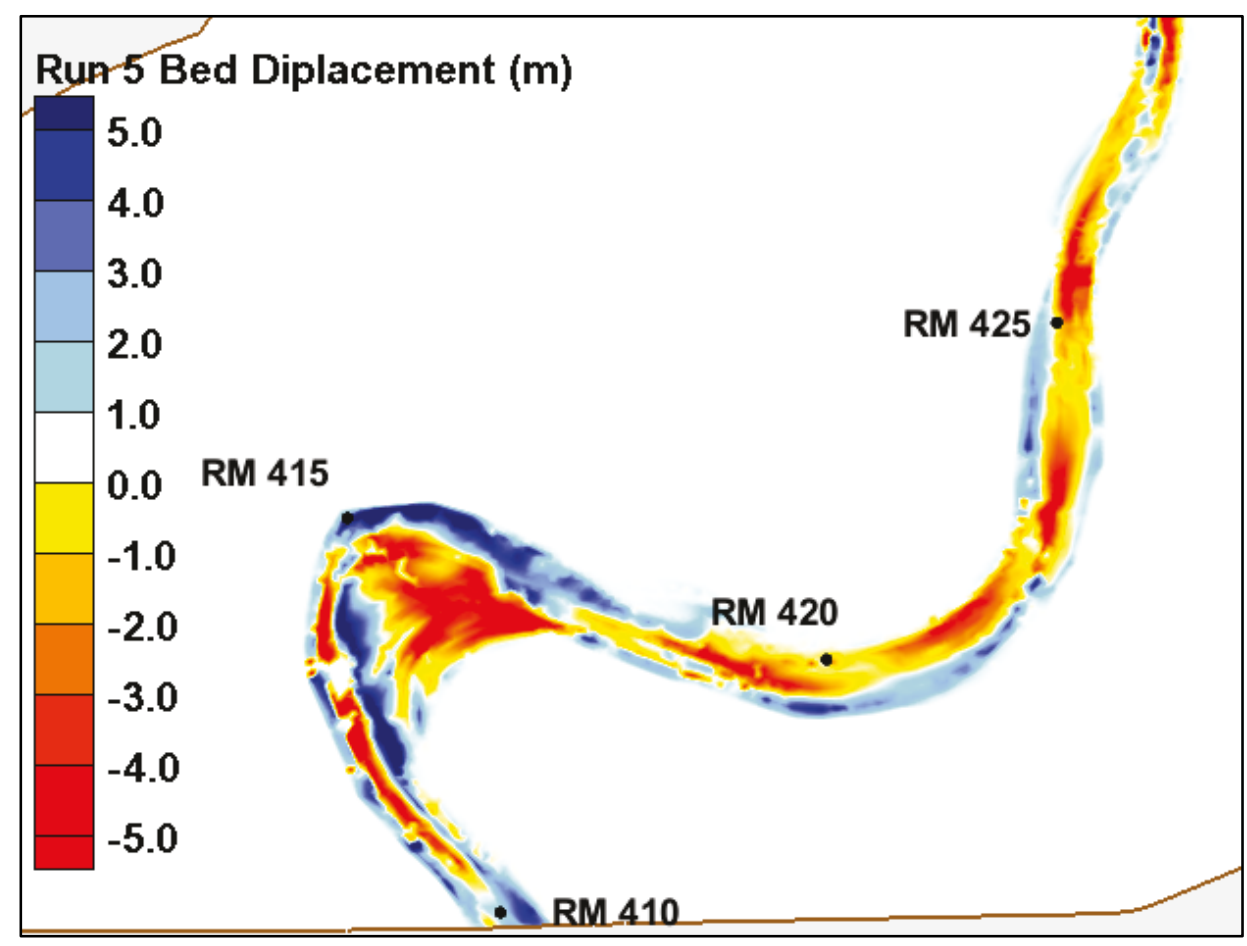


Figure 5-13. 1969-1965 Model Run 6 bed displacement, RM 435 to RM 425.

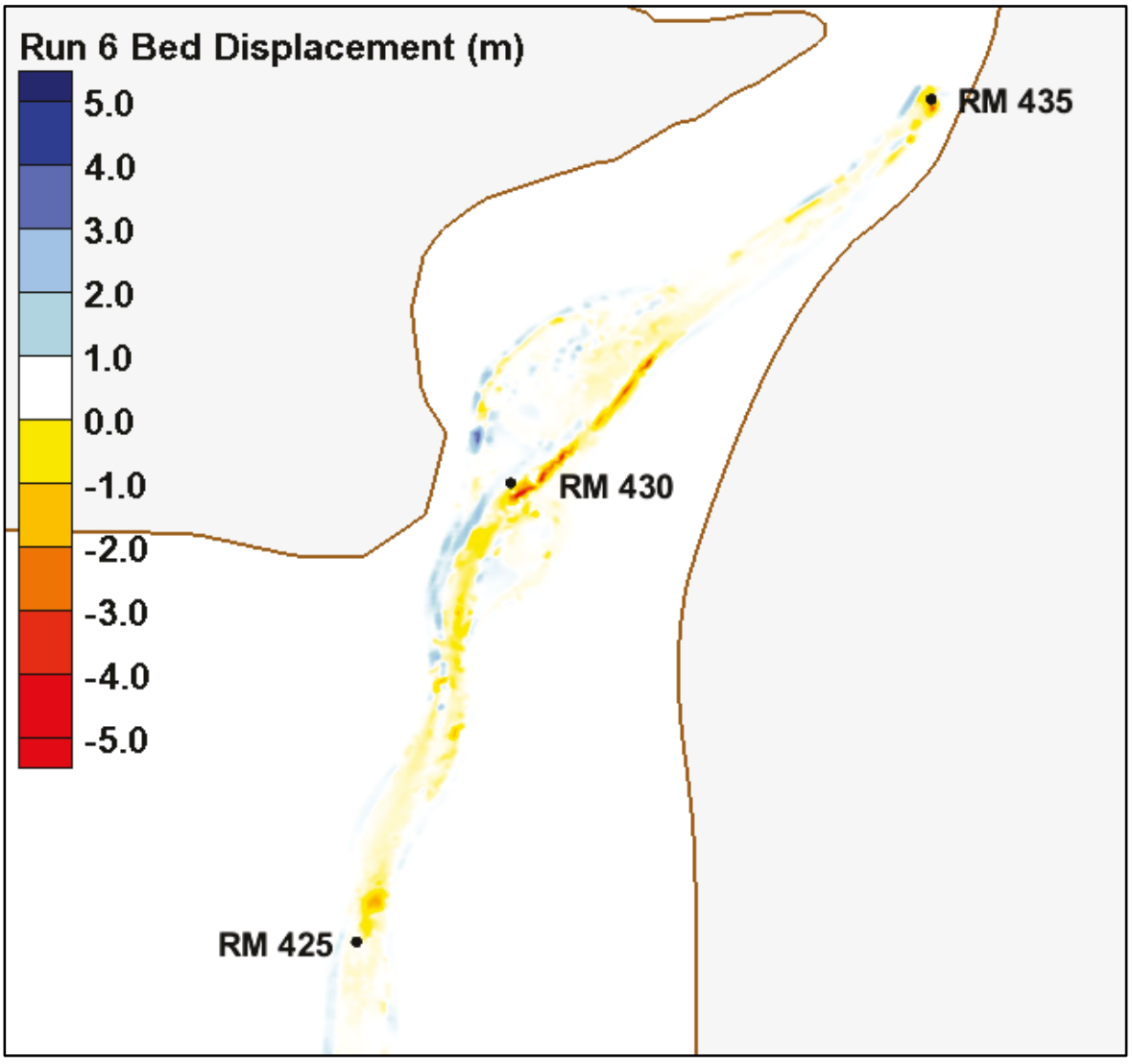

Figure 5-14. 1969-1965 Model Run 6 bed displacement, RM 425 to RM 410.

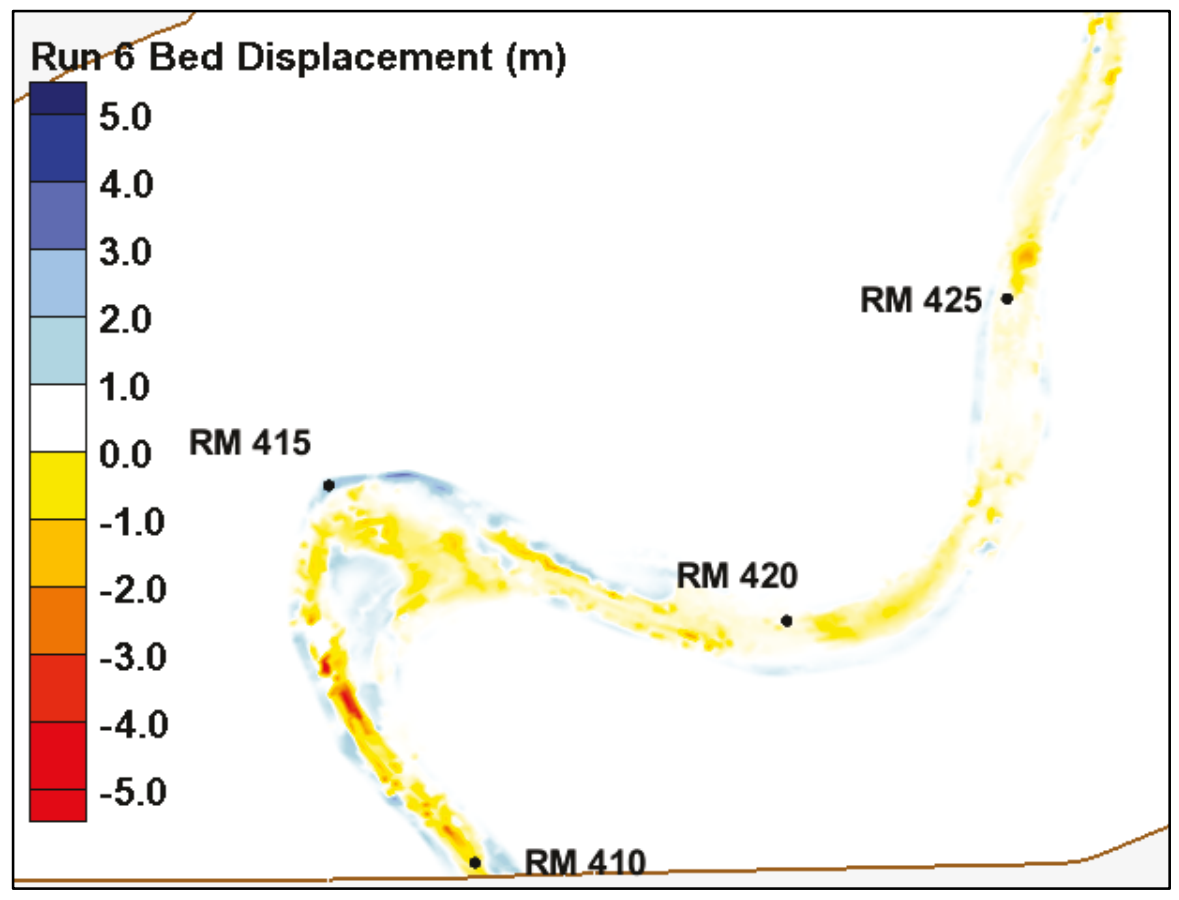


Figure 5-15. 1969-1965 Model Run 7 bed displacement, RM 435 to RM 425.

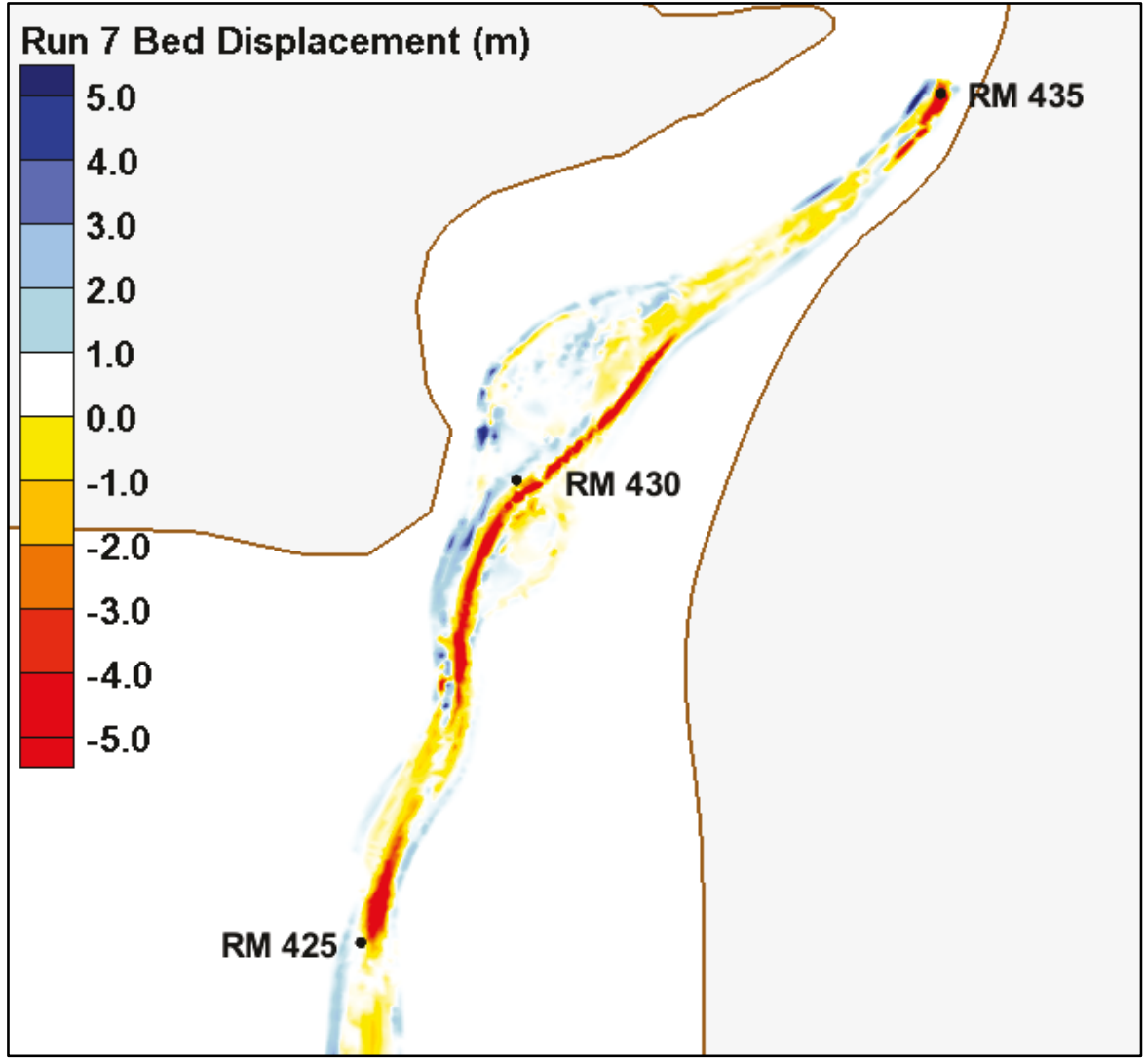

Figure 5-16. 1969-1965 Model Run 7 bed displacement, RM 425 to RM 410.

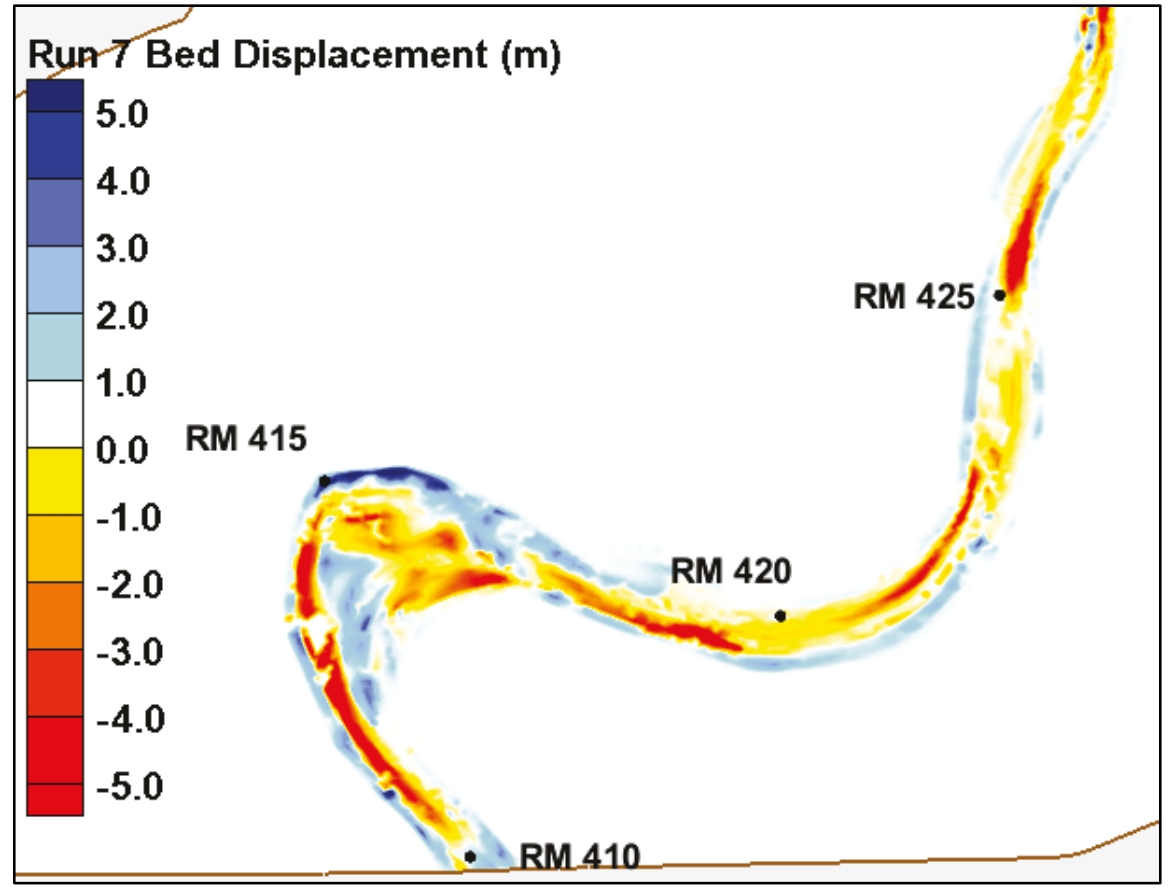


Figure 5-17. 1969-1965 Model Run 8 bed displacement, RM 435 to RM 425.

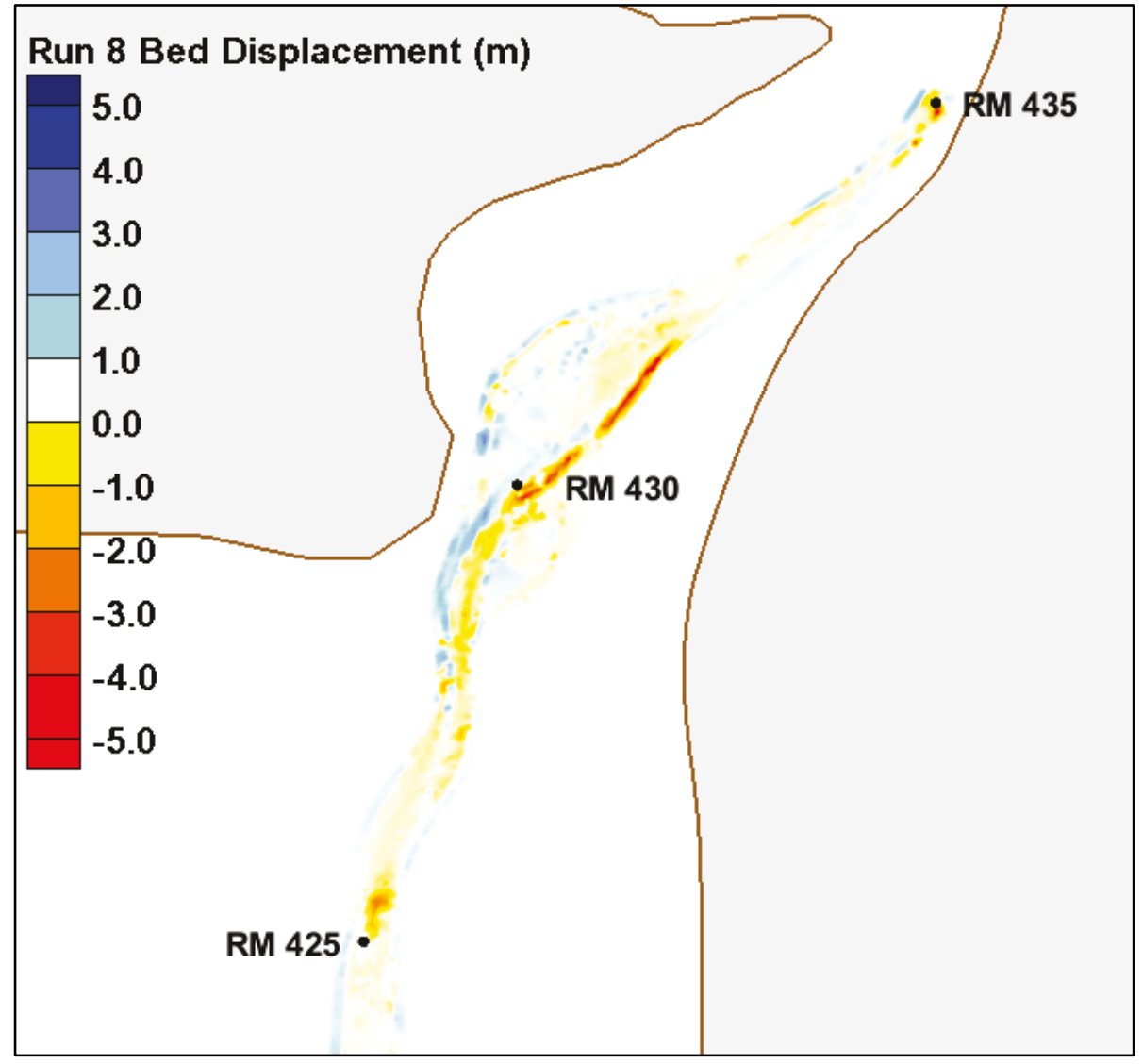

Figure 5-18. 1969-1965 Model Run 8 bed displacement, RM 425 to RM 410.

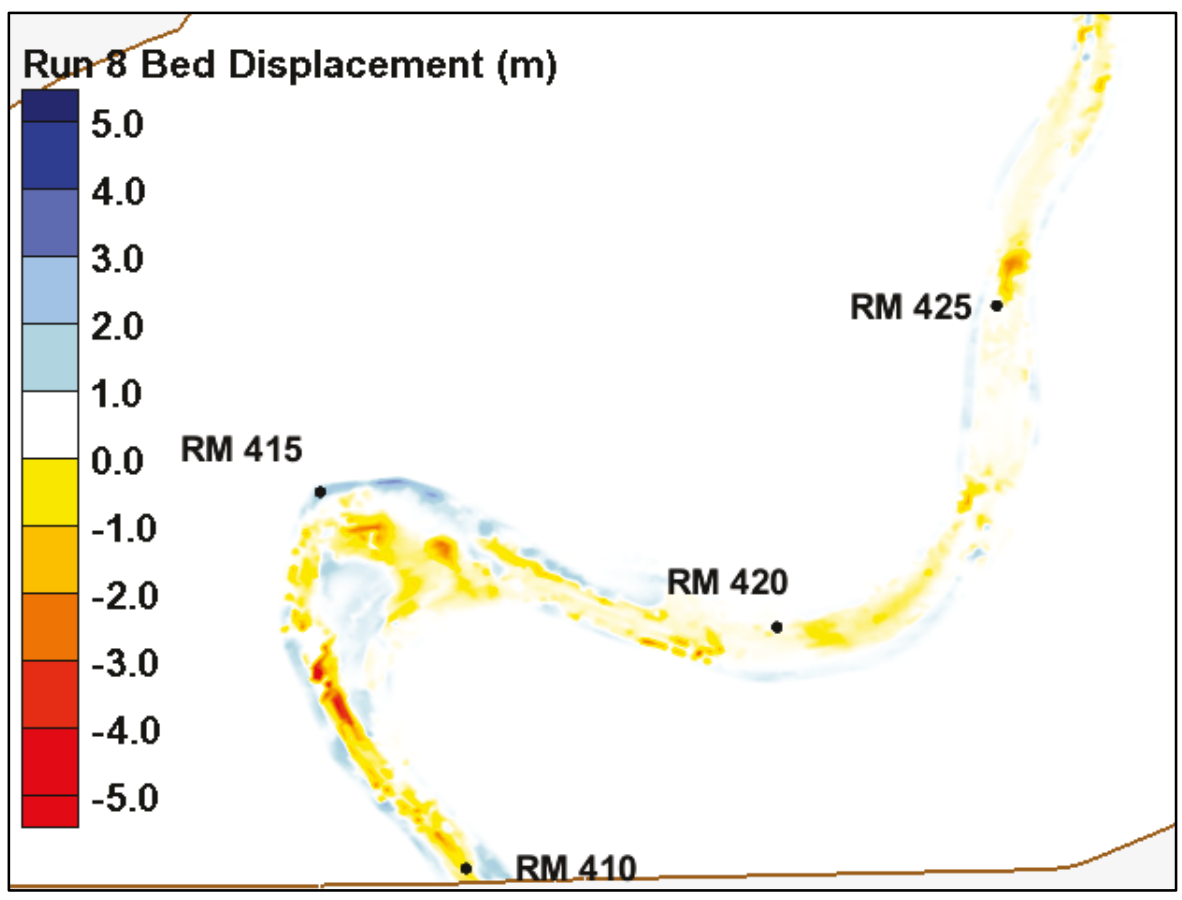




\section{Initial bed specification sensitivity}

The previously shown results are a function of the initial sediment bed specification at the beginning of the model simulations. All of these previously shown results started with the same initial bed obtained by performing a simulation of the 1965 hydrograph using NSE WrightParker, NBE Van Rijn, and HID Wu Wang Jia. To ensure the conclusions would not be influenced by this choice of transport functions for the bed initialization simulation, sensitivity simulations were completed whereby the bed was initialized using NSE Wright-Parker, NBE Van Rijn and HID Wu Wang Jia and using NSE Wright-Parker, NBE Meyer Peter Mueller with Wong Parker Correction and HID Eziagaroff. These two initial bed compositions were then used to simulate the 1965-1969 time period using both of the scenarios stated above (for the bed initialization). A total of four simulations were completed to determine the influence of the initial bed composition on the final results. These results are provided in Figure 5-19 and Figure 5-20.

These sensitivity simulations illustrate the influence of the initial bed composition on the final model results. These sensitivities indicated the patterns of erosion/deposition are largely unchanged due to the bed initializations, but the magnitudes are different. This highlights one of the primary challenges associate with sediment transport modeling: determining an appropriate initial sediment bed. These simulations indicate the erosion/deposition magnitudes shown in the previous section could increase/decrease slightly based on the initial bed specification. For this particular study, the influence of the initial bed is not as significant as this study was less focused on the absolute sedimentation values and more focused on the variation in results between the available transport functions. 
Figure 5-19. Variation in results due to changes in the initialized bed. The left figure is NSE Wright-Parker, NBE Van Rijn, and HID Wu Wang Jia results with NSE Wright-Parker, NBE Van Rijn, and HID Wu Wang Jia spinup bed initialization, and the right figure is NSE Wright-Parker, NBE Van Rijn, and HID Wu Wang Jia results with NSE Wright-Parker, NBE Meyer Peter Mueller with Wong Parker Correction, and HID Eziagaroff spinup bed initialization.
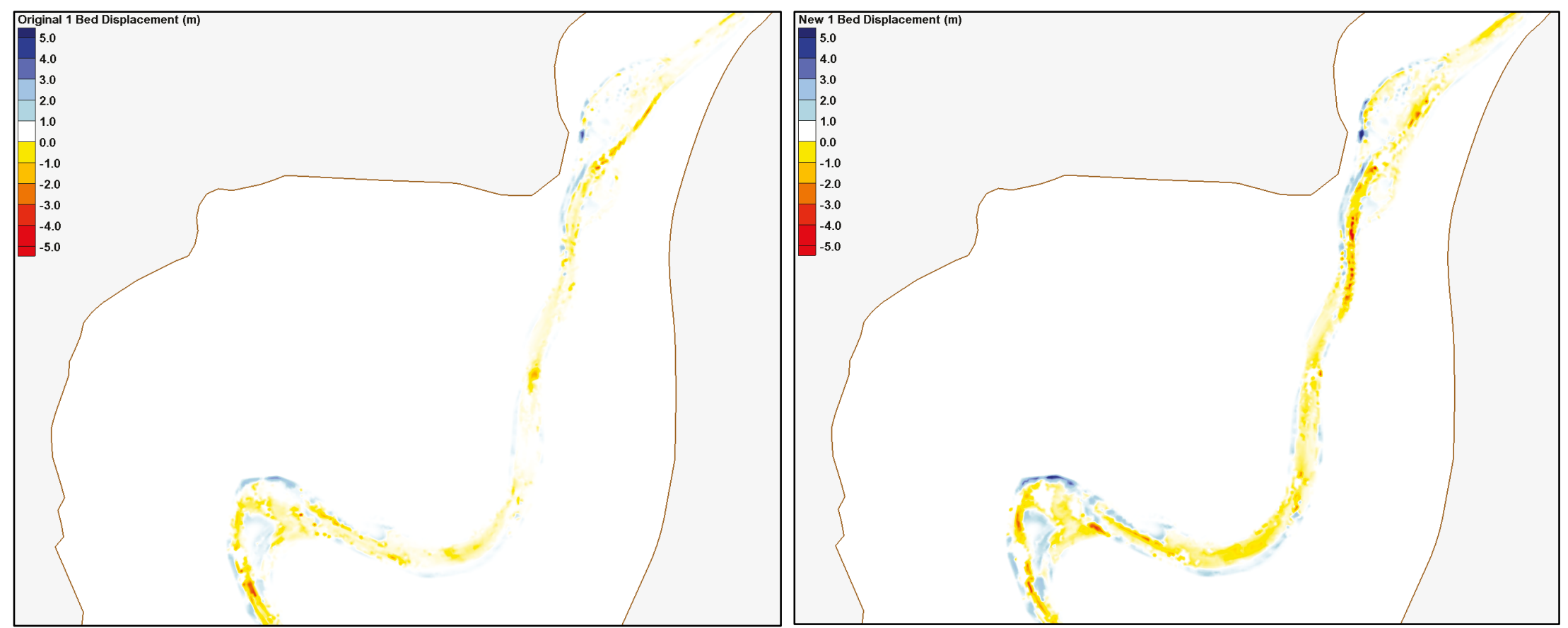
Figure 5-20. Variation in results due to changes in the initialized bed. The left figure is NSE Wright-Parker, NBE Meyer Peter Mueller with Wong Parker Correction, and HID Eziagaroff results with NSE Wright-Parker, NBE Van Rijn, and HID Wu Wang Jia spinup bed initialization, and the right figure is NSE Wright-Parker, NBE Meyer Peter Mueller with Wong Parker Correction, and HID Eziagaroff results with a NSE Wright-Parker, NBE Meyer Peter Mueller with Wong Parker Correction, and HID Eziagaroff spinup bed initialization (right).

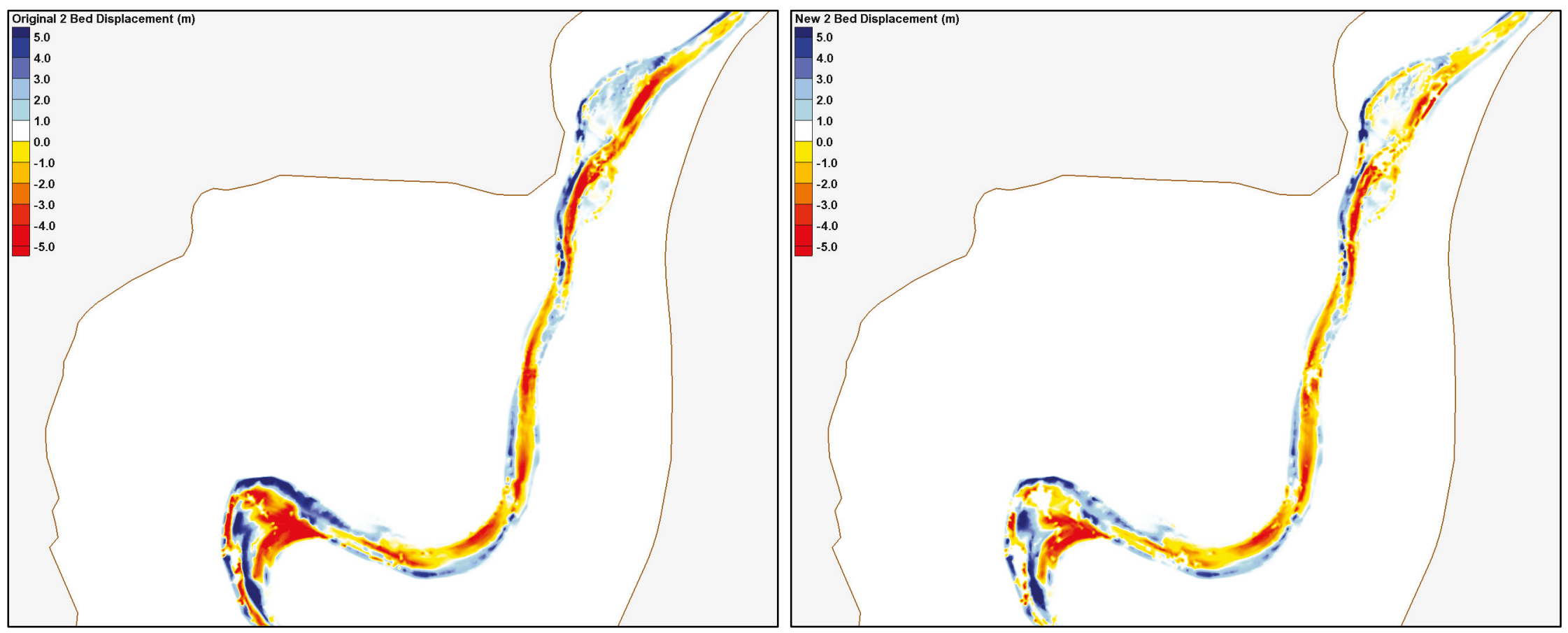




\section{Conclusion}

While limited in data, the water level comparisons indicate the numerical model is adequately replicating the observed values at the Vicksburg, MS, gage. As no additional hydrodynamic data were available, this is a source of uncertainty that could correspondingly impact the sediment transport results. These uncertainties could be reduced if more data were available.

The sediment transport results in general followed similar patterns of erosion/deposition across all model simulations. The primary difference between the simulations was the magnitude of the erosion/deposition. Isolating the model simulations for individual impacts associated with the sediment entrainment, bed-load entrainment, and hiding factor resulted in the following conclusions:

1. The sediment entrainment algorithms have the same general sediment erosional/depositional patterns but do significantly change the magnitude of erosion/deposition. Using the Wright-Parker sediment entrainment function results in a significant increase in the erosion/deposition amounts as compared to the Van Rijn sediment entrainment function.

2. Similar to the sediment entrainment algorithm, the bed-load entrainment algorithms have the same general sediment erosional/depositional patterns but do significantly change the magnitude of erosion/deposition. Using the Meyer Peter Mueller with Wong Parker Correction bed-load entrainment function results in a significant increase in the erosion/deposition amounts as compared to the Van Rijn bed-load entrainment function.

3. The hiding factor algorithm did not change the erosion/deposition patterns but did result in some very minor changes in the local erosion/deposition in select areas. Overall, the hiding factor has minimal influence on the sediment transport results.

Overall, the sediment transport model results generally replicate the patterns observed in the field with some localized variations. Comparison of the magnitude of erosion/deposition depends on the chosen algorithms for sediment entrainment and bed-load entrainment. When using these results, it is important to consider the purpose of the study and the uncertainty in the results. If this numerical model were being utilized for 
dredging purposes, then a comparison of model to observed dredge volumes would show the model more than likely underestimating the dredging requirements, but base versus plan model comparisons could still be useful in indicating the result of a system modification.

In terms of depositional/erosion patterns and magnitudes, the best results were obtained using the Wright-Parker sediment entrainment function and the Meyer Peter Mueller with Wong Parker Correction bed-load entrainment function. The choice of hiding factor had minimal influence on the model results. 


\section{References}

Bernard, B. 1992. Depth-Average Numerical Modeling for Curved Channels. Technical Report HL-92-9. Vicksburg, MS: U.S. Army Research and Development Center.

Biedenharn, David S. 2014. A Review of the Lower Mississippi River Potamology Program. MRG\&P Report No.1. Vicksburg, MS: U.S. Army Engineer Research and Development Center.

Brown, Gary L. 2008. "Approximate Profile for Nonequilibrium Suspended Sediment.” Journal of Hydraulic Engineering 134(7): 1,010-1,014.

Brown, Gary L. 2012a. "A Quasi-3D Suspended Sediment Model Using a Set of Correction Factors Applied to a Depth Averaged Advection Diffusion Equation.” In Proceedings, IIHR 3rd International Shallow Flows Symposium, University of Iowa.

Brown, Gary L. 2012b. "Modification of the Bed Sediment Equations of Spasojevic and Holly (1993) to Account for Variable Porosity, Variable Grain Specific Gravity, and Nonerodable Boundaries." In Proceedings, IIHR 3rd International Shallow Flows Symposium, University of Iowa.

van Rijn, L. C. 1984. “Sediment Transport, Part I: Bed Load Transport.” J. Hydr. Engrg. 110(10): 1431-1457. DOI:10.1061/(ASCE)0733-9429(1984)110:10(1431)

Wright, S., and G. Parker. 2004."Flow Resistance and Suspended Load in Sand-Bed Rivers: Simplified Stratification Model." Journal of Hydraulic Engineering 130(8): 796.

Wu, W. M., S. S. Y. Wang, and Y. F. Jia. 200o. "Nonuniform Sediment Transport in Alluvial Rivers." J. Hydr. Res., IAHR 38(6): 427-434. 


\section{Appendix A: Mississippi River Hydrographic Survey Plates for the Racetrack Reach (1969)}

Figures A-1 to A-3 are the Mississippi River Hydrographic Survey Plates for the Racetrack Reach for 1969. These data were used to initialize the numerical model mesh elevations. 
Figure A-1. Racetrack Reach RM 434.9 to 430.9.

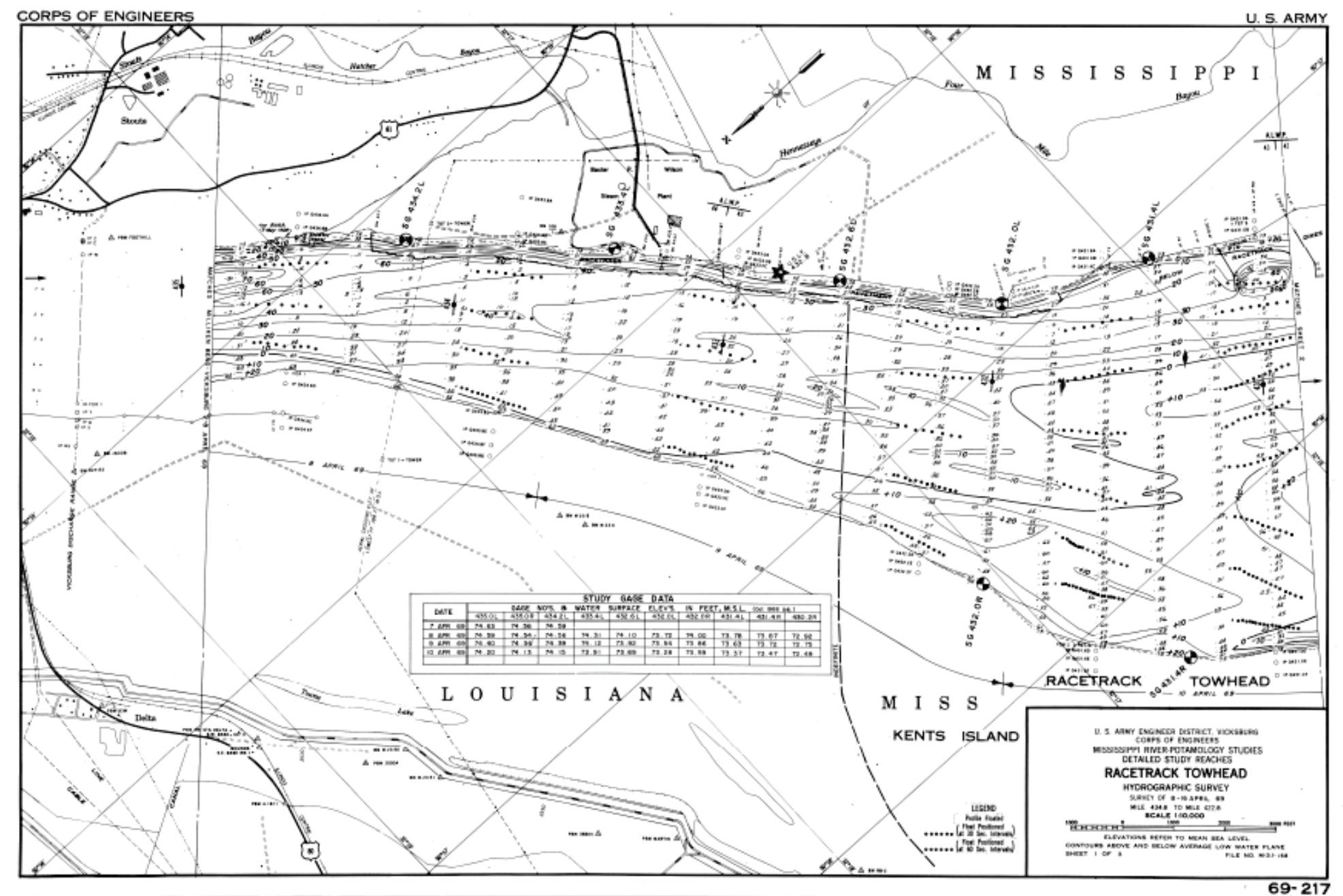


Figure A-2. Racetrack Reach RM 430.9 to $\mathbf{4 2 6 . 8 .}$

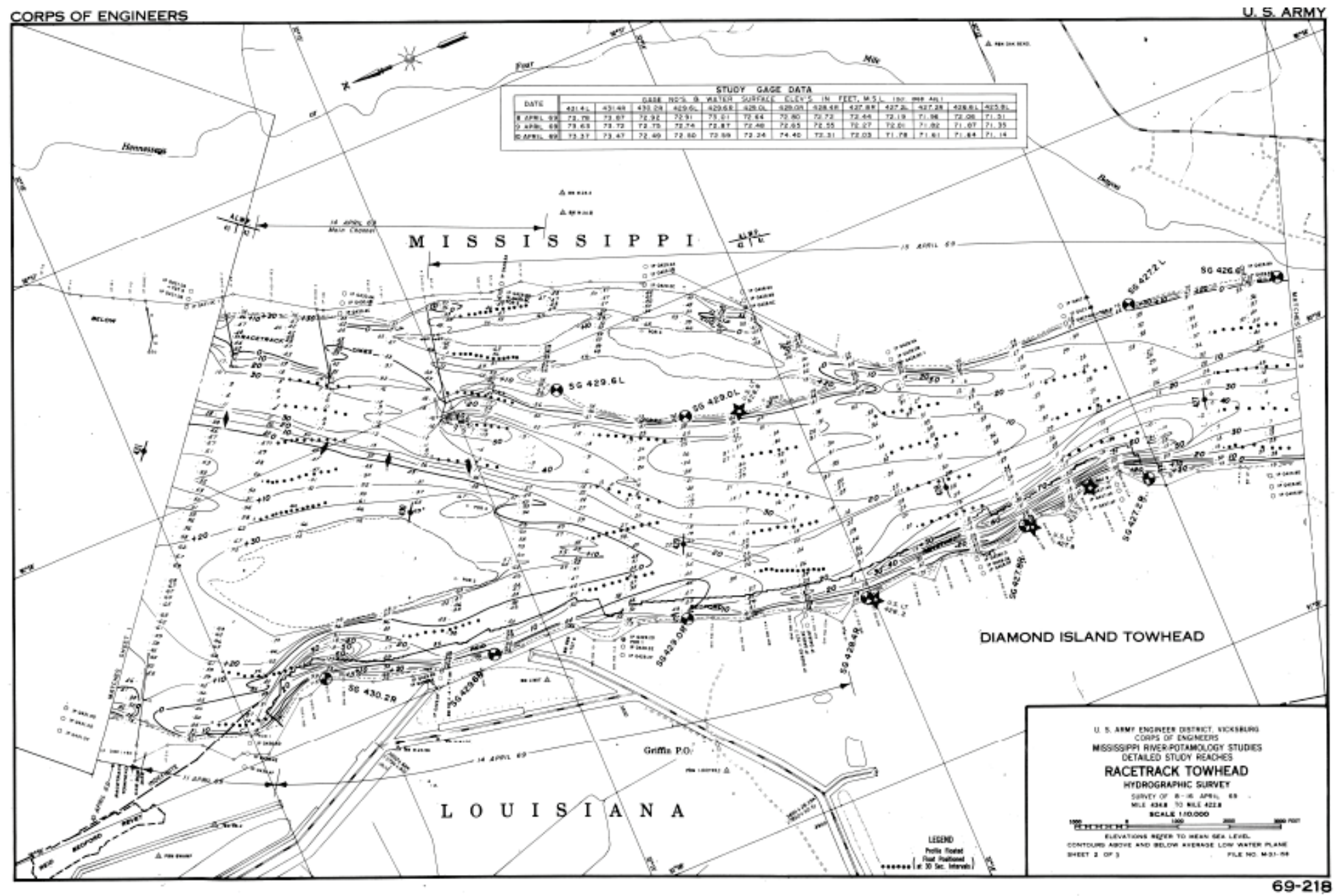


Figure A-3. Racetrack Reach RM 426.8 to 422.9.

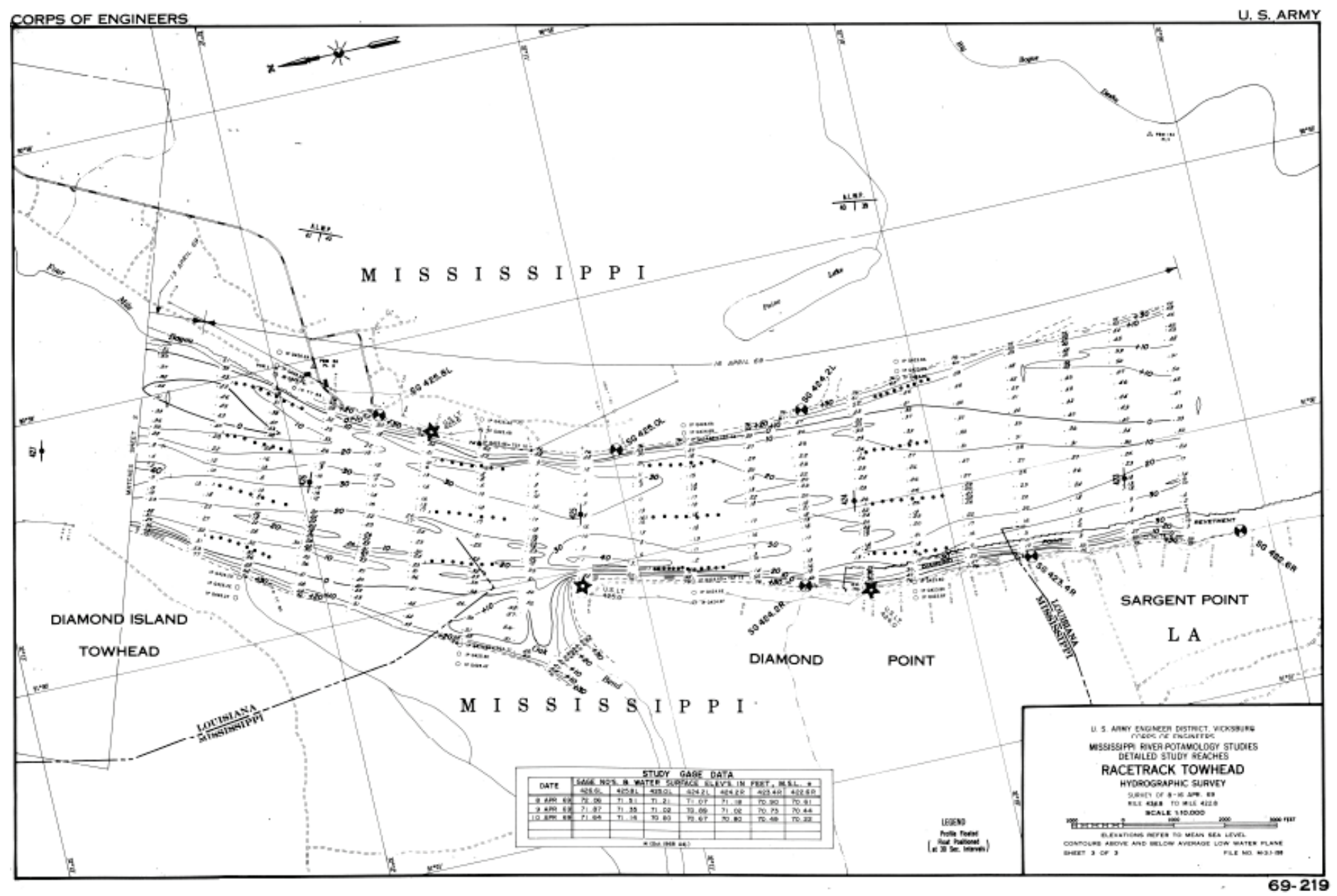




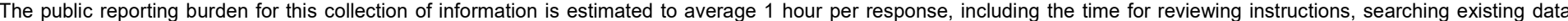

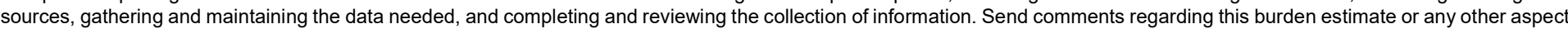

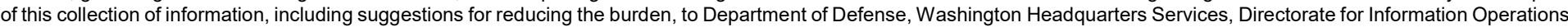

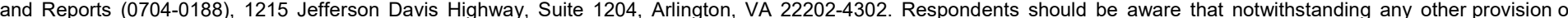
law, no person shall be subject to any penalty for failing to comply with a collection of information if it does not display a currently valid OMB control number. PLEASE DO NOT RETURN YOUR FORM TO THE ABOVE ADDRESS.

\begin{tabular}{l|l|l}
\hline $\begin{array}{l}\text { 1. REPORT DATE } \\
\text { August } 2018\end{array}$ & $\begin{array}{l}\text { 2. REPORT TYPE } \\
\text { Final Report }\end{array}$ & 3. DATES COVERED (FrOm - To)
\end{tabular}

\section{TITLE AND SUBTITLE}

Two-Dimensional Hydraulics and Sediment Transport Modeling of the Racetrack Reach of the Mississippi River, 1965-1969 5a. CONTRACT NUMBER

5b. GRANT NUMBER

5c. PROGRAM ELEMENT NUMBER

5d. PROJECT NUMBER

470711

5e. TASK NUMBER

5f. WORK UNIT NUMBER

8. PERFORMING ORGANIZATION REPORT NUMBER Valley Division 1400 Walnut Street Vicksburg, MS 39180

MRG\&P Report No. 20

\section{USACE MVD}

\section{SPONSOR/MONITOR'S} REPORT NUMBER(S)

\section{DISTRIBUTION/AVAILABILITY STATEMENT}

Approved for public release; distribution is unlimited.

\section{SUPPLEMENTARY NOTES}

\section{ABSTRACT}

This report documents the development, calibration, and validation of a numerical model for the Racetrack Reach of the Mississippi River between the Vicksburg, MS, Interstate-20 Bridge and approximately 12 miles downstream conducted for the U.S. Army Corps of Engineers, Mississippi Valley Division, Vicksburg, MS. The investigation was conducted via a combination of historical field data collection and numerical modeling of the hydraulics and sediment transport. The objectives were to model flow conditions and sediment transport from 1965 through 1969 and compare to historical surveys from 1965 and 1969 on the Mississippi River. A detailed Adaptive Hydraulics model was developed for this reach of the river. The model domain extends from 10 miles upstream of the Mississippi River Bridge in Vicksburg, MS, to 24 miles downstream of the bridge and adjacent portions of the Mississippi River and its floodplain. Unsteady flow simulations were evaluated for the time from 1965 through 1969. For this particular model application, the Wright-Parker suspended sediment entrainment function and the Meyer Peter Mueller with Wong Parker Correction bed-load entrainment function results best replicated the depositional/erosion patterns and magnitudes. The choice of hiding factor did not have a noticeable impact on the results.

\section{SUBJECT TERMS}

Hydraulic models, Mathematical models, Mississippi River, Numerical analysis, Sediment transport

\section{SECURITY CLASSIFICATION OF:}

\begin{tabular}{|l|l|l|l}
\hline a. REPORT & b. ABSTRACT & c. THIS PAGE & \multirow{2}{*}{ ABSTRACT } \\
Unclassified & Unclassified & Unclassified & SAR
\end{tabular}

18. NUMBER OF 19a. NAME OF RESPONSIBLE PERSON \begin{tabular}{l|l} 
PAGES & Ty V. Wamsley
\end{tabular}

53 19b. TELEPHONE NUMBER (Include area code) 601-634-5062 